\title{
Choices that Matter: Coalition Formation and Parties' Ideological Reputations
}

\author{
Albert Falcó-Gimeno \\ University of Barcelona \\ afalcogimeno@ub.edu
}

\author{
Pablo Fernandez-Vazquez \\ University of Pittsburgh \\ pablo.fernandez@pitt.edu
}

Forthcoming in Political Science Research and Methods

\begin{abstract}
This paper examines how a party's decision to enter a coalition government affects voter perceptions of the party's policy position. We argue that, for the decision to change voter beliefs, it must be at odds with voters' prior opinions about the party. Specifically, the party must join a coalition that is not the one voters perceive as the ideologically closest option. Otherwise, the party's action simply confirms voters' pre-existing beliefs. Hence, whether or not joining a coalition alters voter attitudes depends on the type of alternative coalitions the party could enter. We test the hypothesis using three complementary empirical strategies: a cross-country analysis of party reputations in five coalition-prone European countries, individual panel data, and a quasi-experimental test. All three empirical tests provide support for our claim. This paper contributes to our understanding of voter information processing, coalition politics, and party competition.
\end{abstract}




\section{Introduction}

A well-functioning representative democracy relies on citizens' capacity to process, evaluate, and react to the information that political parties generate through their behavior. It enables voters to hold incumbents accountable and identify where parties stand on policy issues (Adams, 2012). In parliamentary democracies, membership in a coalition government constitutes a potential source of information about a party's ideology. Indeed, parties tend to choose coalition partners with similar ideologies and therefore the decision to join a coalition constitutes a cue into the party's policy position (Glasgow et al., 2012; Martin and Stevenson, 2001).

This paper analyzes whether a party's decision to enter a coalition changes voters' perceptions of where the party stands on issues. It builds on previous work by Fortunato and Stevenson (2013) who show that coalition partners tend to be perceived to be close on a left-right dimension. It is also motivated by more recent research that has expanded the analysis to other policy issues (Adams et al., 2016) and has examined the relative impact of coalition membership for junior and senior coalition partners (Fortunato and Adams, 2015).

We argue that entering a coalition does not always change voter perceptions of the party's policy position. We identify a key condition that needs to be met for voter attitudes to shift: the party's decision must be at odds with voters' priors about the party. Specifically, the party must choose to form a coalition that is not the one that voters perceived to be the ideologically closest option. Otherwise, if the party chooses the coalition that voters already identified as the most ideologically congruent choice, the party's action confirms voters' beliefs and voter opinions do not change.

We follow three complementary strategies to test this empirical prediction. We first analyze the effect of joining a coalition using party-level data on the left-right reputation

of political parties in five coalition-prone Western European countries. We also leverage individual panel data from Norway to show how the effect of joining a coalition cabinet 
depends on each voter's prior opinion. Finally, we take advantage of the random ordering in which survey respondents are contacted to compare the issue placement given to the British and German liberals right before and right after joining a government coalition. All three types of empirical evidence support our argument: a coalition member's perceived position only changes when the party joins a coalition different from the one that voters considered to the ideologically closest option among all viable alternatives. Otherwise, voter perceptions remain unchanged.

Our paper makes a novel contribution to the literature on the impact of coalition membership on voters' attitudes (Adams et al., 2016; Bargsted and Kedar, 2009; Duch et al., 2010; Fortunato and Stevenson, 2013; Fortunato and Adams, 2015; Spoon and Klüver, 2016). We advance this line of research by proposing an explicit theoretical mechanism to explain why coalition formation can modify voter opinions about parties in the cabinet that highlights the importance of the alternatives they had (Indridason, 2011). Such mechanism generates heterogeneous expectations that are borne out by the data. The scope of our argument, moreover, is broad since it can be applied beyond coalition formation processes. Empirically, we examine our hypothesis using several different types of data, including an explicit causal identification strategy by taking advantage of a quasi-experimental test.

Our paper has important implications for democratic theory and party politics. We show that an elite-driven process like that of forming a new government has consequences for mass politics. Voters observe the new cabinet and update their opinion of where parties stand accordingly, either confirming or adjusting their previous perceptions. Hence, even if multiparty governments tend to reduce the clarity of responsibility (Powell and Whitten, 1993), we show that coalition partners are, at least, held accountable for their decision to join the executive. This is good news for democratic politics, as it suggests that citizen attitudes toward parties are responsive to a core dimension of party behavior like the decision to form a government. Political parties, moreover, must incorporate the consequences for voter perceptions in their calculus to join a cabinet or not, since entering a government may affect 
the party's ideological image. Parties therefore face a trade-off: in cases where participation in a coalition may damage a party's policy reputation, seeking office now can undermine the pursuit of votes in the future (Fortunato, 2017; Müller and Strøm, 1999; Sagarzazu and Klüver, 2017).

\section{Argument}

There is a renewed interest among political scientists in the question of how voters form and update their beliefs about where parties stand on policy issues (Adams, 2012; Adams et al., 2011; Fernandez-Vazquez, 2014). Dalton and McAllister (2015) show that, even though parties' left-right reputations tend to be rather stable, changes in citizens' perceptions of party positions are more common in fragmented systems. In parliamentary democracies, the choice of coalition partners is a potential source of information about a party's policy position. Joining a coalition government is an observable decision with tangible consequences for policy outcomes (e.g. Bräuninger, 2005; Cusack, 1997; Iversen and Soskice, 2006; Klingemann et al., 1994). In addition, there is consistent evidence that parties prefer coalition partners that have similar ideological positions (Glasgow et al., 2012; Martin and Stevenson, 2001). Hence, the choice of coalition partners constitutes an informative signal of where the party stands ideologically. Recent work has provided evidence that joining a multi-party cabinet can have consequences for voter perceptions about the party. Fortunato and Stevenson (2013) show that coalition partners tend to be perceived to be ideologically close. Adams et al. (2016) extend this finding to the issue of European integration and Fortunato and Adams (2015) show that coalition agreements matter more for the perceived placement of junior partners than for the Prime Minister's party. The effect of coalition behavior on perceived party placements has also been recently documented for signals indicating preferred wouldbe partners in case a coalition forms after elections (Falcó-Gimeno and Muñoz, 2017). We take these findings as the starting point to make a general argument about the effect of 
coalition formation on voter opinions of where parties stand.

Despite the remarkable degree of stability in the formation of coalitions following elections, we find many instances in which parties change coalition partners from one term to the next (Armstrong and Duch, 2010). ${ }^{1}$ Moreover, while voters tend to have a solid knowledge of the composition of their current government, they find it hard to recall the coalition choices parties made in the past (Fortunato and Stevenson, 2013; Fortunato et al., 2014). Therefore, there is a clear potential for current coalition behavior to affect voters' view of parties' positions.

We argue, though, that entering a coalition does not always change voter opinions about the party: Even if the decision provides information about the party, such information may not change voter perceptions. This paper identifies the condition under which joining a coalition cabinet changes voters' perceptions about where the party stands. If the party's decision is consistent with voters' opinions about the party, the choice will reinforce voters' priors and thus will not alter voter beliefs. Voters only change their perceptions when the choice of coalition partners is at odds with their initial opinions about the party. In that case, voters' beliefs adjust in line with the party's decision. ${ }^{2}$

The following example illustrates the logic of our argument. Take a party that has the option of entering either a coalition $L$ or a coalition $R$. The party decides to join the $L$ cabinet. This signals that the party is ideologically closer to $L$ than to $R .^{3}$ Voter perceptions, however, only change if voters initially believed that the party was closer to $R$ than to $L$. Otherwise the revealed preference for $L$ only reinforces prior beliefs and does not change opinions. Hence, the empirical prediction that we test is the following:

1 According to Armstrong and Duch's (2010) figures, the probability that at least one coalition partner will remain in government after an election is consistently higher than the probability that the same coalition will be formed. Parties, thus, often remain in power but with a new coalition partner.

2 Note that, in fact, the same coalition choice may be the most ideologically consistent with voters' priors after election $t$ but not after election $t+1$ if the set of alternative options changes between the two elections. Hence, it is possible according to our argument that voters change their perception of a party's position even if it picks the same coalition partners.

3 While reasons other than ideological proximity may explain parties' coalition choices, unless the specific reason for the choice is known, the decision to enter $L$ at least increases the probability that the party is closer to $L$ than to $R$. 
Hypothesis A party's decision to join a coalition government is more likely to change voter perceptions of where the party stands on policy issues if voters believed that there was an ideologically closer alternative coalition that the party could have chosen instead.

To test this prediction, we combine three complementary empirical strategies. We first take a broad cross-country across-time approach to analyze the impact of joining a coalition government in five European parliamentary democracies between 1979 and 2011. Our second strategy exploits differences in perceptions across voters. Using panel data from Norway we compare the effect of joining a coalition between voters who thought that the coalition was the most ideologically congruent choice and those who did not. Finally, we take advantage of the random ordering in which survey participants are contacted to evaluate whether there are differences in opinions among respondents interviewed immediately before and immediately after the coalition forms.

\section{A Cross-Country Test of the Argument: The Case of Five West European Countries from 1979 to 2011}

This section presents a cross-country empirical test of our argument. While the argument about the effect of coalition membership on voter perceptions applies to any policy dimension, this cross-country test focuses on parties' left-right reputations for reasons of theoretical relevance and data availability. The left-right dimension provides a good summary of European party positions on economic and social issues (Benoit and Laver, 2012) and it is a relevant predictor of voting decisions (Van der Eijk et al., 2005; Lachat, 2008). From a pragmatic point of view, survey data on parties' left-right positions are available for several European countries over a long period of time. Indeed, among all European countries that have frequent coalition governments, we center our attention on those with a long-standing 
tradition of including left-right placement items in their election study questionnaires: Norway, Sweden, Denmark, Germany and the Netherlands. ${ }^{4}$

The outcome of interest are voter perceptions of party positions following the formation of a new cabinet. We operationalize voter perceptions of a party's left-right position as the average left-right placement given to that political party among the whole sample of respondents. The two main data sources we use are the European Voter Database (EVD), a collection of European national election studies, and the Comparative Study of Electoral Systems (CSES). ${ }^{5}$ We draw the survey data from post-election waves to maximize the probability that, by the time the survey is fielded, it is already clear which government has formed or is likely to form. ${ }^{6}$ The countries and years included in our dataset are listed in Table 1.

Table 1: Countries included in the analyses and years in which post-election surveys where conducted.

\begin{tabular}{ll}
\hline \hline Country & Years \\
\hline Denmark & $1994,1998,2001,2005,2007,2011$ \\
Germany $^{7}$ & $1998,2002,2005,2009$ \\
Netherlands & $1981,1982,1986,1989,1994,1998,2002,2003,2006,2010$ \\
Norway & $1977,1981,1985,1989,1993,1997,2001,2005,2009$ \\
Sweden & $1979,1982,1985,1988,1991,1994,1998,2002,2006$ \\
\hline \hline
\end{tabular}

For each party-year pair, we compute the variable Position $_{t+1}$, which denotes the average left-right placement given to the party in the post-election survey. Position, , in turn, reflects the average placement in the previous post-election survey. To give an example, for German

${ }^{4}$ Coalitions are also frequent in Austria, Belgium, or Portugal, among others, but in these countries there are not enough consecutive post-election surveys that measure voter perceptions of where parties stand on the left-right dimension.

${ }^{5}$ Further information about the EVD database can be found here: http://dx.doi.org/10.4232/1.3911 [last accessed September 2016]. Since the last elections covered by the EVD took place in 1998, we have updated our data with more recent surveys. These newer surveys come from either country-specific election studies or from the Comparative Study of Electoral Systems (CSES). Most of these surveys use a $0-10$ scale. For surveys using a $1-10$ axis instead, the data have been rescaled.

6 The process of coalition formation may in some cases drag on for months, and therefore post-election survey waves could sometimes be fielded before the final coalition agreement is reached. If so, ours is a conservative approach since our estimations will underestimate the effect of the membership in a coalition on a party's policy image.

7 German national election studies have asked respondents to place parties on a left-right scale since 1976. Before 1998, however, this survey question is placed in a pre-election wave (see http://zacat.gesis.org/ [Last accessed May 9th 2017]). 
parties in 2009, Position $_{t+1}$ refers to the average party placement in the 2009 post-election survey, while Position $_{t}$ captures the placement in the 2005 post-election wave. Both variables range from 0 to 10, where 0 indicates a far left position and 10 a far right one.

We test our hypotheses using the change in a party's average left-right placement as our dependent variable: The variable Update takes the difference between the latest post-election placement $\left(\right.$ Position $\left._{t+1}\right)$ and the placement in the previous post-election survey $\left(\right.$ Position $\left._{t}\right){ }^{8}$ This variable returns how far to the right (positive values) or to the left (negative values) the average voter perception of the party has changed. It ranges from -10 (leftmost shift) to 10 (rightmost shift). Membership in the government that forms after the election is indicated by the dummy variable Party Status, which equals 1 if it enters the government and 0 otherwise.

In order to test the argument in the paper, we define a dichotomous variable, Alternative, which takes the value of 1 if the party does not join the coalition that voters considered to be the ideologically closest option. To elaborate this dummy variable, we first identify the set of viable cabinets that can form after each election. Taking all the potential governments, we estimate a model of government formation following Glasgow and Golder (2015). ${ }^{9}$ For each formation opportunity, we rank each potential government according to the predicted probability of formation and define the set of viable cabinets as the decile of potential governments with the highest probability of forming. ${ }^{10}$ For instance, in the government formation opportunity of Sweden 1994, a total of 127 governments were hypothetically possible. After estimating the formation model, we categorized as viable the 13 governments with the highest formation probability. ${ }^{11}$

8 We also estimate a model in levels using the post-election position Position $_{t+1}$ as our dependent variable. The results are offered in the Supporting Information section.

9 We run a conditional logit regression on a sample of formation opportunities in 18 countries from 1945 to 2012, in which we include the following covariates: presence of an incumbent party in the government, presence of the parliamentary largest party, total seat share of the government, total seat share squared, presence of the previous PM party, incumbent coalition, minority coalition, minimal winning coalition, and number of parties in the coalition (these are Glasgow and Golder's (2015) covariates except for the variable indicating the ideological polarization of the government, which we do not include because our theoretical framework is precisely concerned with an ideological choice by the party joining a coalition).

${ }^{10}$ In formation opportunities where the total number of potential governments is less than 10 , we consider all options as feasible.

${ }^{11}$ In the Supporting Information we present a robustness check in which we opt for a different procedure: 
Second, we calculate the perceived left-right position of every viable coalition by using Gamson's law (Gamson, 1961). Applied to policy formation, Gamson's law entails that the policy position of a government can be equated to the seat-weighted average of the policy positions of the members of the coalition. ${ }^{12}$ As a robustness check, we replicate our analysis estimating a coalition's overall left-right position as the unweighted average of all coalition partners' positions. This alternative operationalization does not affect the empirical findings. ${ }^{13}$ These estimates of the perceived position of each possible coalition allows us to define the viable coalition that voters consider to be the ideologically closest option. If the party joins such coalition, the variable Alternative takes the value of 0 . If the party chooses a coalition different from the one voters considered as the ideologically logical choice, Alternative equals 1.

Finally, since the effect of joining the government depends on the ideological leaning of the cabinet that forms, we specify the variable Distance $_{R G}$, defined as the perceived ideological distance between the party and the government that forms, measured before the election. ${ }^{14}$ Positive values of Distance $_{R G}$ indicate that the government is perceived to be more rightleaning than the party, while negative values imply otherwise.

\section{Results}

With these data, we estimate the following empirical model:

all minimal wining coalitions are defined as viable. Results do not hinge on this definition.

${ }^{12}$ We have calculated the position of the government that emerges as the seat-weighted average of the cabinet members' positions even for minority governments. It is true that minority governments need the consent of opposition parties to make policy (Falcó-Gimeno and Jurado, 2011), but given the possibility these governments have to build law-specific agreements with other parties, we think it is most reasonable to consider cabinet members only in calculating the position of the minority government.

${ }^{13}$ These results can be found in the Supporting Information

${ }^{14}$ Hence Distance $_{R G}$ captures the perceived ideological proximity between a government and a party before that coalition enters office. 


$$
\begin{aligned}
\text { Update }=\beta_{1} & +\beta_{2} \text { Distance }_{\mathrm{RG}}+\beta_{3} \text { Party Status }+\beta_{4} \text { Alternative } \\
& +\beta_{5} \text { Party Status } * \text { Alternative } \\
& +\beta_{6} \text { Distance }_{\mathrm{RG}} * \text { Party Status } \\
& +\beta_{7} \text { Distance }_{\mathrm{RG}} * \text { Alternative } \\
& +\beta_{8} \text { Distance }_{\mathrm{RG}} * \text { Party Status } * \text { Alternative }
\end{aligned}
$$

The variable Party Status captures the effect of entering the government on the party's left-right reputation. It is interacted with Distance $_{R G}$ since the information provided by the decision to join the cabinet depends on the government's overall left-right position. To test the theoretical argument, we also interact PartyStatus with Alternative. This allows to compare the impact of government participation between the scenario where the argument predicts a change in voter perceptions (Alternative $=1)$ and the one where it predicts stability $($ Alternative $=0)$. To facilitate the interpretation of the results of a regression equation with a triple interaction, we present marginal effects at different values of our key moderating variable as well as predicted changes in the dependent variable (Brambor et al., 2006). ${ }^{15}$

Table 2 presents a first test of the argument. It displays the effect of joining a cabinet that is located one standard deviation to the right of the party in two scenarios: (1) when the party confirms voters priors by joining the coalition that voters considered to be the ideologically closest option (Alternative $=0$ ), and $(2)$ when the party chooses a cabinet that is not the one that voters considered to be the most ideologically congruent choice (Alternative $=1$ ). The cell entries in the "Marginal Effect" column report the estimated shift in the perceived left-right position of the party. Positive values indicate that voters shift their placement of the party to the right. Negative values, on the other hand, imply that voters place the party closer to the left.

These estimates show that, when the party confirms voters priors by choosing the coali-

\footnotetext{
${ }^{15}$ As Brambor et al. (2006) note, evidence about conditional relationships require to go beyond the traditional results table and convey quantities of interest like the marginal effect of $\mathrm{X}$ on $\mathrm{Y}$ for different values of the modifying variable. In any case, the estimated regression coefficients are reported in the Supporting Information.
} 
Table 2: Marginal effect of entering a government depending on whether the party joins the option that voters consider to be the ideologically closest alternative. Scenario: the government is one standard deviation to the right of the focal party.

\begin{tabular}{ccc}
\hline Scenario & $\begin{array}{c}\text { Marginal } \\
\text { Effect }\end{array}$ & $\begin{array}{c}\text { Std. } \\
\text { Error }\end{array}$ \\
\hline Alternative $=0$ & -0.10 & 0.60 \\
Alternative $=1$ & $0.40 *$ & 0.11 \\
\hline \hline
\end{tabular}

Marginal effects and standard errors in their respective columns. Marginal effect computed for a value of Distance $_{\mathrm{RG}}$ equal to one standard deviation to the right in the distribution of that variable, i.e. 2.85 units on the 0-10 left-right scale.

tion that is considered to be the ideologically closest (Alternative $=0$ ), entering that coalition has no discernible effect on perceptions of parties' left-right positions. Even if the coalition is one standard deviation away in ideological distance, i.e. 2.85 units to the right on a 0-10 scale, voter perceptions barely change. In contrast, when the party does not select the coalition that voters considered to be the most ideologically congruent option (Alternative $=1$ ), voter opinions about the party change significantly: The party's average placement shifts 0.4 units towards the position of the coalition that it has joined. In addition, we can reject the null hypothesis of no change. Joining a coalition that is 1 point away in a 0 to 10 scale, thus, barely moves the perception of the party if this was the most ideologically proximate but it does significantly shift its left-right placement if it was not the most proximate choice: there is around a $15 \%$ reduction in the perceived distance between the party and its coalition partners under these circumstances. This is a substantively large change when compared to the generally strong stability in European parties' left-right images (Dalton and McAllister, $2015)^{16}$ and more than triples the effect of changes in parties' declared left-right placements in their manifestos on voters' perceptions of the parties' positions (Adams et al., 2011).

\footnotetext{
${ }^{16}$ Our estimates imply that, when the party does not choose the option that voters saw as the ideologically closest option, joining a cabinet located one standard deviation away in ideological distance produces a notable $138 \%$ increase over the normal volatility in party images. This percentage results of comparing the effect on voter opinions we estimate, 0.40, with Dalton and McAllister (2015) estimate that the median shift in average perceptions across two consecutive elections is only 0.29 points on a $0-10$ scale. Dalton and McAllister's data overlaps substantially with ours.
} 
Figure 1 provides a full comparison of the effect of entering a cabinet in each scenario. It reports the predicted shift in the party's left-right image as a function of the distance between the party and the government that forms ( Distance $\left._{\mathrm{RG}}\right)$. Positive values on the horizontal axis indicate that the government has a more right-wing reputation than the party and vice versa. On the vertical dimension, positive values indicate that the party's perceived position shifts to the right. The left-hand plot refers to a context where the party confirms voters priors by joining the coalition that voters perceived to be most ideologically congruent choice among the viable alternatives. The plot on the right, in turn, reflects the change in perceptions when the party does not choose the coalition that voters perceived to be the most ideologically congruent option.

Figure 1: Predicted change in a party's left-right reputation after joining the government. 95\% Confidence Intervals.
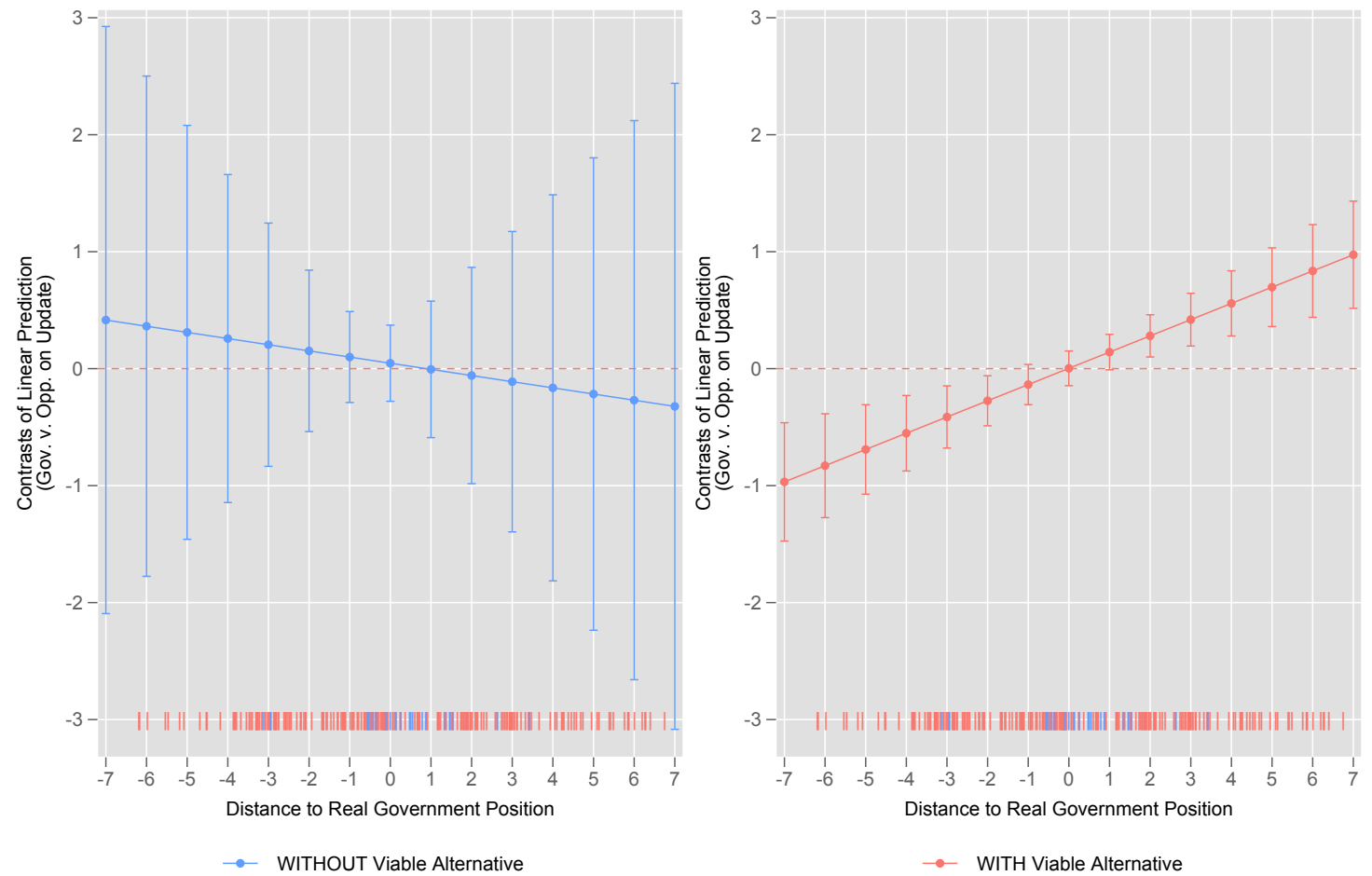

NOTE: The left plot displays the predicted shift in the average left-right placement for a party that confirms voters' priors by choosing the coalition that was perceived to be ideologically closest among the viable alternatives. The right plot refers to a party whose choice is at odds with voters priors. The horizontal axes indicate the left-right distance between the coalition that forms and the focal party.

The predicted shifts show that the decision to join a coalition does not always change 
voter perceptions about the party. If the party chooses the coalition that voters perceive to be the most congruent option (left plot), the effect of joining the cabinet is minimal, in the opposite direction, and we cannot reject the null hypothesis of no effect at all. In contrast, when the party's decision is at odds with voters priors (right plot), entering the government reshapes voters' perceptions: forming a coalition that is more right-wing than the party makes voters shift their opinion about the party to the right, and vice versa. While the predicted shifts are not statistically different across the two scenarios, the empirical results still offer the following conclusion: Joining a cabinet that is not the one voters considered to be the ideologically closest option changes voter opinions about the party. On the other hand, if the party's decision confirms voters' priors, government participation does not have consequences for the party's reputation.

The same empirical pattern emerges in several robustness tests. First, we have analyzed whether results change if we adopt a different definition of what constitutes a viable potential government. We show that defining viable alternatives as the set of all minimal winning coalitions does not alter results. Second, we have checked whether the empirical pattern holds if we do away with Gamson's Law when computing the overall ideological position of a coalition. Using the unweighted arithmetic mean so that all coalition partners contribute equally to the overall coalition position does not change results. This finding suggests that the empirical pattern reported above is not driven by larger parties contributing more to the estimated position of coalition governments. In addition, we use a simulation-extrapolation approach (Lederer and Küchenhoff, 2006; Benoit et al., 2009) to confirm that our findings are not an artifact of measurement error. Finally, we have tested the hypothesis using a regression model in levels instead of in first differences. In this model the outcome variable is defined as the party's average left-right placement after the election instead of the change in placement. The same empirical pattern emerges using this alternative model specification. The evidence from these robustness checks is reported in the Supporting Information. 


\section{Individual Panel Data Evidence: The Case of the Center Party in Norway 2005}

The previous empirical analysis offers party-level evidence on how joining a coalition changes the party's left-right reputation. The same aggregate trend, however, is consistent with multiple patterns of individual-level changes. Our argument predicts a different response to a party's decision to enter the government depending on each voter's prior beliefs about the party. In other words, the same party decision can have different consequences for two voters with diverging initial opinions about the party. For a voter who already thinks that the cabinet joined is the ideologically closest option that the party had, the party's decision corroborates the voter's perception of where the party stands. Hence, this voter has no reason to change her opinion about the party. In contrast, for a voter who thought that there was an ideologically closer alternative to the cabinet chosen, the party's decision is inconsistent with her prior belief and therefore drives her to adjust her opinion about where the party stands.

In this section we use individual-level panel data to exploit variation in voters' prior opinions and offer further evidence in support of the argument. We focus on the government formation process in Norway in 2005 for two main reasons. First, following the 2005 election, the Norwegian Center Party (Senterparteit) had the choice between two viable potential coalitions. ${ }^{17}$ It could form a left-leaning coalition with the Norwegian Labor Party (DNA) ${ }^{18}$ and the Socialist Left Party (SV). ${ }^{19}$ Alternatively, the Center Party could join a right-leaning

\footnotetext{
${ }^{17}$ Founded in 1920, the Sp is an agrarian party that is typically considered moderate from a left-right perspective. Since 1963, the Sp had been part of most of the right-of-the-center coalition cabinets that formed in Norway, in alternation with single-party social-democratic governments. According to Allern and Aylott (2009), the Sp was originally anchored in the non-socialist bloc until the early 2000s .

${ }^{18}$ Since 2011, Arbeiderpartiet (Ap).

${ }^{19}$ The Center Party had reached a pre-election agreement with these two left parties to run separate lists but with a common policy agenda, which was explicitly considered as a commitment to form a coalition government in case they jointly reached the absolute majority of seats in the Storting (Norwegian parliament). The so-called red-green coalition eventually managed to win a narrow majority and formed a minimum winning coalition.
} 
cabinet with the Conservative Party $(\mathrm{H})$, the Christian Democratic Party (KrF), and the Liberal Party $(\mathrm{V})$ - plus the participation or implicit aquiescence of the Progress Party (FrP). ${ }^{20}$ Second, while some voters perceived that the Center Party was closer to the rightleaning coalition, others considered that the left-leaning cabinet was the most ideologically consistent option. Hence, whatever the Center Party's final decision, it confirmed some voters' priors and spurred others to adjust their beliefs.

The Center Party eventually decided in favor of the left-leaning cabinet. This choice was not a matter of political survival but the expression of an ideological preference: The party "concluded that its goals were more attainable with new allies on the left" (Allern and Aylott, 2009, 273). Hence, this case is a good candidate to test whether or not the choice of coalition partners (left or right-leaning) affects voters perceptions of where the party stands on the left-right scale. According to our argument, the Center Party's choice will change the perceptions of voters who had thought that the party was closer to the conservative coalition. On the other hand, it predicts no opinion change among citizens who already thought that the Center Party was closer to the left-leaning parties.

To test this empirical implication, we employ a panel survey from the Norwegian Election Study (2001-2005). This study consists of a pre-election wave in 2001 and a post-election one in 2005. ${ }^{21}$ From 2001 to 2005 (before and after the formation of the left-leaning coalition), the average left-right position attributed to the Center Party moved slightly to the left, from 4.44 to 4.34. Using panel data allows us to identify which voters in particular changed their perceptions. Figure 2 shows the distribution of the position attributed to the Center Party $(\mathrm{Sp})$ in $2001(t)$ and after the 2005 elections $(t+1)$ for two groups of respondents. The panel on the left refers to citizens who considered in 2001 that the Center Party was ideologically

\footnotetext{
${ }^{20}$ Even if the FrP was unlikely to join a coalition government, "[i]t was clear that the Progress Party would become a centre-right coalition's primary support party, potentially providing a majority in numerous policy areas" (Allern and Aylott, 2009, 273).

${ }^{21}$ The fieldwork dates are Jun. 1st to Sep. 1st for the 2001 election study and Sep. 13th to Dec. 14th for the 2005 one. For further reference visit valgundersokelse.nsd.uib.no/webview/index/en/MyServer/ Panelundersoekelser.d.5/Norwegian-Election-Study-2001-2005-panel/fStudy/NSD1352
} 
closer to a left-leaning coalition. ${ }^{22}$ Hence, for this group the Sp's choice of partnering with the Labor and Socialist parties was consistent with their prior opinions about the party. The second group (right panel) is composed of respondents who thought that the Sp was closer to the center-right coalition. Our argument implies that only voters in this second group will shift their perception of the Sp toward the position of the coalition that formed. This is precisely what we see in Figure 2: while the pre and post-coalition distributions on the left-hand panel overlap almost perfectly, the post-coalition $(t+1)$ density in the right-hand side panel has clearly shifted to the left of the initial $t$ curve. $^{23}$

Figure 2: Distribution of left-right placements attributed to the Norwegian Center Party (Sp) before $(t)$ and after $(t+1)$ forming a left-leaning coalition. The left panel portrays the opinions of those who already in 2001 considered that the party was ideologically closer to a left coalition. The right panel reports the perceptions of those who initially believed that a right-leaning coalition was the most ideologically consistent choice.

Table 3 shows that the difference in the average update across these two groups is statistically significant. The group who thought that the right-leaning coalition was a more ideologically congruent alternative subsequently shifted its opinion 0.8 points toward the left. By contrast, those for whom the Sp had chosen the ideologically closest option did not change their perception. For this group the average update is only 0.09 toward the right and it is not statistically significantly different from zero.

Table 3: Mean Comparison T-Test of Update for Two Groups

\begin{tabular}{rccc}
\hline \hline Group & Obs. & Average Shift & {$[95 \%$ Conf. Interval $]$} \\
\hline Sp closer to left-leaning coalition & 547 & 0.09 & {$[-0.04,0.22]$} \\
Sp closer to right-leaning coalition & 135 & -0.80 & {$[-1.13,-0.47]$} \\
\hline Difference & & 0.89 & {$[0.58,1.20]$} \\
\hline \hline
\end{tabular}

In the Supporting Information we show that the pattern of perception changes that we

${ }^{22}$ The perceived distances are again calculated according to Gamson (1961). We subtract the attributed left-right position to the Sp from i) the seat-weighted average of the positions of the DNA, SV, and Sp to calculate the distance to the real government and from ii) the seat-weighted average of the positions of the $\mathrm{H}$, the $\mathrm{KrF}$, the $\mathrm{FrP}$, and the Sp to calculate the distance to the alternative coalition.

${ }^{23}$ Another way to look at this is to compare the distribution of changes in opinions about the Sp across these two groups of respondents. We do this graphically in the Supporting Information. 
find is not a mechanical consequence of the fact that those who perceived that the left-leaning coalition was the most ideologically congruent choice also tended to place the party further to the left than those who had thought that the right-leaning alternative was the closest option. We also rule out the alternative explanation that the change in opinions about the Center Party responded to an objective shift in party manifestos.

\section{The Timing of Survey Responses as a Natural Ex- periment: The British and German Liberals}

As a final test of the theoretical argument, we adopt a quasi-experimental identification strategy to ensure that the estimated effect of joining the government is driven by the coalition formation itself and not by any other factor. For that purpose, we take advantage of the random ordering in which survey respondents are interviewed to compare the issue placement given to a political party immediately before and after it joins a coalition government. Fielding a public opinion survey takes time and a new government may form while a post-election wave is being administered, which allows to classify respondents according to whether they completed the questionnaire by the time the new cabinet was announced or not. We leverage the fact that the timing in which respondents are contacted is orthogonal to their political predispositions to identify whether forming a coalition changes perceptions of where the party stands. ${ }^{24}$ Hence, our strategy is to compare the average perception of the party among respondents interviewed immediately before and those contacted immediately after the coalition announcement.

We examine two cases for which our theory has opposite predictions, the British Liberal Democrats in 2010 and the German Free Democratic Party in 2009. These two parties faced a similar strategic choice as they could choose between two alternative viable coalitions: the Liberal Democrats could partner with either the Conservative Party or with Labour

\footnotetext{
${ }^{24}$ The Supporting Information presents randomization checks comparing the two groups.
} 
(and some minor parties), and the German Free Democrats could either select the Christian Democratic Union or join a cabinet with both the Socialdemocratic Party and the Left Party. The key difference is that, while the German liberals chose the option that most citizens considered to be the ideologically closest — a coalition with the Christian Democrats - , the British liberals chose the Conservatives even though most voters at the time thought that Labour had more similar issue stances. Hence, the argument predicts a shift in the issue reputation of the British Liberal Democrats but no change for the German Free Democrats.

\section{The British Liberal Democrats after the 2010 Election}

For the first time in 36 years, the 2010 British general election did not provide any party with a parliamentary majority. Two viable options were on the table: ${ }^{25}$ a government between the Conservatives and the Liberal Democrats, and another between the latter and the Labour Party with the support of other minor parties. Before the Liberal Democrats eventually chose to ally with the Conservative Party, most British citizens considered that the Liberal Democrats were closer to Labour. Table 4 presents the perceived issue placements of all three major British parties before the coalition formed and reports the percentage of citizens who thought that the Liberal Democrats were closer to the Conservative Party than to Labour. Only a minority of respondents perceived the Conservatives to be the most ideologically similar choice. The decision of the Liberal Democrats was thus at odds with (most) citizens' priors about the party, and therefore the argument predicts that (most) voters adjusted their beliefs accordingly.

We test our claim using the post-election wave of the British Election Study Internet Panel. ${ }^{26}$ Out of 13, 356 respondents, $84 \%$ were interviewed before the coalition was announced (May 11th) and the remaining $16 \%$ afterwards. ${ }^{27}$ The post-election questionnaire included

\footnotetext{
${ }^{25}$ A minority government by the Conservatives, the plurality winners, was not seen as feasible given the context of financial crisis and the prospect of legislative defeats: spiegel.de/opinion-a-uk-minority-governmentwould-not-last-long.html and news.bbc.co.uk/uk_news/politics/election_2010.stm.

${ }^{26}$ Additional information about this survey: www.bes2009-10.org/bes-data/MEMOCIPS.pdf.

${ }^{27}$ For a reference on the timing of the coalition announcement, see cnn.com/05/11/uk.cameron.conservative.
} 
Table 4: Pre-coalition average issue placements and percentage of respondents that considered that the Liberal Democrats were closer to a coalition with the Conservatives.

\begin{tabular}{lcccc}
\hline \hline & $\begin{array}{c}\text { LibDem } \\
\text { placement }\end{array}$ & $\begin{array}{c}\text { Conserv } \\
\text { placement }\end{array}$ & $\begin{array}{c}\text { Labour } \\
\text { placement }\end{array}$ & $\begin{array}{c}\text { \% Conservative } \\
\text { closer }\end{array}$ \\
\hline taxes and spending $^{1}$ & 5.5 & 4.3 & 5.8 & $31 \%$ \\
fighting crime tradeoff $^{2}$ & 4.8 & 4.0 & 5.1 & $36 \%$ \\
\hline \hline
\end{tabular}

Data sources: (1) 2010 pre-election British Election Study internet survey, (2) pre-election British Election Study face-to-face survey.

a $0-10$ issue scale regarding the trade-off between fighting crime and protecting individual rights where 0 indicates a "tough on crime" position. With these data, we compare the average perception of the Liberal Democrats between those interviewed before and those contacted after the coalition agreement is announced.

The evidence supports our prediction (Table 5). The perceived position of the Liberal Democrats shifts closer to the Conservative Party: Respondents interviewed after the coalition is announced see the Liberal Democrats as tougher on crime than those contacted immediately before. To ensure that this shift is driven by the formation of a coalition and not part of a trend common to all parties, we run a placebo test to check whether the perceived position of other parties also changes. As can be seen in Table 5, issue placements are not significantly different for either the Labour Party or the Conservatives. Hence, the formation of the cabinet changes perceptions about the party that made a choice that was not consistent with most voters' priors, but not about the other cabinet member or the main opposition party.

\section{The German Free Democratic Party in 2009}

In contrast with the British Liberals, our argument predicts no update in voter perceptions regarding the German Free Democratic Party (FDP) in 2009. While the FDP could also choose between two alternative multiparty cabinets, one with the Christian Democrats 
Table 5: Average party placement before and after the coalition forms. Issue: Trade-off between fighting crime and protecting individual rights. One-tailed difference in means ttest. Alternative hypothesis: after coalition, Liberal placement is closer to the "tough on crime" endpoint.

\begin{tabular}{lccc}
\hline \hline & $\begin{array}{c}\text { before coalition } \\
\text { placement }\end{array}$ & $\begin{array}{c}\text { after coalition } \\
\text { placement }\end{array}$ & Difference \\
\hline Liberal Democrats & 4.8 & 4.7 & $0.10^{*}$ \\
Conservative party & 3.1 & 3.2 & -0.09 \\
Labour party & 5.0 & 4.9 & 0.09 \\
$\mathrm{~N}$ & 11,231 & 2,125 & \\
\hline \hline & t-test: ${ }^{*} \mathrm{p}<.05$
\end{tabular}

(CDU/CSU) and another with both the Social Democratic Party (SPD) and The Left, it opted for the coalition that most voters considered to be the ideologically consistent choice (CDU/CSU and FDP). Table 6 indicates that, before the coalition formed, most citizens already thought that the FDP was closer to a coalition with the CDU/CSU. Hence, choosing a cabinet with the Christian Democrats was consistent with most voters' priors, and hence the argument predicts no significant change in the average placement of the party.

Table 6: Pre-coalition average issue placements and percentage of respondents that considered that a coalition with CDU/CSU was ideologically closer.

\begin{tabular}{lcccc}
\hline \hline & $\begin{array}{c}\text { FDP } \\
\text { placement }\end{array}$ & $\begin{array}{c}\text { CDU } \\
\text { placement }\end{array}$ & $\begin{array}{c}\text { SPD } \\
\text { placement }\end{array}$ & $\begin{array}{c}\text { \% CDU/CSU } \\
\text { closer }\end{array}$ \\
\hline left-right & 5.7 & 6.5 & 3.7 & $75 \%$ \\
taxes \& spending & 3.5 & 4.3 & 5.4 & $66 \%$ \\
libertarian dimension & 5.6 & 6.2 & 4.3 & $58 \%$ \\
nuclear policy & 3.7 & 3 & 5.9 & $64 \%$ \\
\hline \hline
\end{tabular}

Data Source: pre-election wave 2009 German Longitudinal Election Study (GLES). ${ }^{28}$

The analysis reported in Table 7 supports this prediction. Respondents contacted after the coalition agreement was announced do not have statistically different opinions about the position of the Free Democrats on any of the four issues included in the questionnaire. ${ }^{29}$ ${ }^{29}$ The CDU/CSU-FDP coalition was announced on $\begin{array}{llll}\text { October } & 24 \text { th } & 2009 \\ \text { (http://news.bbc.co.uk/2/hi/europe/8323651.stm). } & \text { Of the participants in the post-election wave of }\end{array}$ 
Table 7: Average placement of the German Free Democratic Party before and after the coalition is announced. German Longitudinal Election Study, post-election wave. Onetailed difference in means t-test. Alternative hypothesis: post-coalition FDP placement is closer to the $\mathrm{CDU} / \mathrm{CSU}$ position.

\begin{tabular}{lccc}
\hline \hline & $\begin{array}{c}\text { before coalition } \\
\text { placement }\end{array}$ & $\begin{array}{c}\text { after coalition } \\
\text { placement }\end{array}$ & Difference \\
\hline left-right & 5.9 & 5.8 & 0.06 \\
taxes \& spending & 3.1 & 2.9 & 0.18 \\
libertarian dimension & 5.9 & 6.0 & -0.08 \\
nuclear policy & 3.2 & 3.2 & 0.05 \\
$\mathrm{~N}$ & 894 & 1,221 & \\
\hline \hline & t-test: ${ }^{*} \mathrm{p}<.05$ & &
\end{tabular}

Thus, joining a coalition government did not change the policy reputation of the FDP.

Taken together, the examples of the British Liberal Democrats and the German Free Democrats offer additional support for our argument that joining a multiparty government only changes perceptions of a party's policy preferences when voters thought that the party had an ideologically closer viable alternative.

\section{Discussion}

In this paper we have analyzed how a party's decision to join a coalition government influences voter perceptions of where the party stands ideologically. We have proposed an argument that identifies the condition under which the party's decision changes voter perceptions. It posits that voters only adjust their beliefs when the party's decision conflicts with their prior opinions about the party. All three types of empirical evidence we leverage - time-series cross-section, panel, and quasi-experimental-offer support for our claim: they show that joining a multi-party cabinet does not always change voter perceptions of the party's position. If the party enters the coalition that voters already considered to be

the 2009 German Election Study, 894 were contacted before the coalition formed and 1221 were interviewed after. 
the most ideologically congruent choice among the viable alternatives, voter opinions do not shift. In contrast, when voters thought that the party could have joined a more ideologically consistent coalition than the one it actually chose, the party's decision has important consequences for voter opinions about the party.

In this paper we have identified a general pattern of differences in the impact of coalition governments. Future work could extend this research agenda to analyze whether individuallevel traits modulate the effect of coalition formation on citizens' opinions. It is plausible to expect, for example, that voters interested in politics will be the most responsive to party decisions to join a cabinet since they are the most likely to become aware of these party decisions (Delli Carpini and Keeter, 1996; Prior, 2005, 2007). At the same time, political predispositions can introduce biases in information processing that might moderate the impact of coalition agreements on citizen opinions (Zaller, 1992).We thus believe our paper can spur relevant new research on the consequences of party behavior for individual attitudes.

Our findings also provide a theoretical mechanism and offer evidence for why participation in a coalition may have consequences in the upcoming election. Joining a cabinet may change voter perceptions of what the party stands for and thereby induce partisan sorting along ideological lines (Adams et al., 2012; Levendusky, 2009). This could help explain why coalition partners tend to lose votes in the next election (Fortunato, 2017; Nannestad and Paldam, 2003; Stevenson, 2002) or even why the formation of certain coalitions is associated with a decline in support for democracy (Singh and Thornton, 2016). Indeed, our argument generates the testable prediction that, everything else equal, the electoral repercussions of cabinet participation will be larger for a party who had alternative options that voters considered to be more ideologically similar. Note also that, while it has been argued that multi-party governments reduce the clarity of responsibility and undermine retrospective voting (Powell and Whitten, 1993; Tavits, 2007), our evidence indicates that cabinet partners are at least held accountable for their coalitional choices through shifts in their ideological 
reputation. Such electoral consequences of coalition participation feed into the calculations of party elites. Insofar as changes in voter opinions about the party can damage the party's electoral prospects, party officials face a dilemma between obtaining office benefits now and incurring vote losses in the future (Müller and Strøm, 1999).

The robust empirical support for our general argument has implications beyond government formation processes. Our theoretical approach helps explain why voting decisions on legislation can have consequences for party reputations (Harbridge and Malhotra, 2011; Hetherington, 2001; Grynaviski, 2010). Legislators have at least two possible choices: to pass new legislation or to keep the status quo, and therefore their roll-call votes can help reveal their ideological preferences (Clinton et al., 2004; Clinton, 2012; Poole and Rosenthal, 2007). Among all roll-call votes, moreover, our argument predicts that voter opinions are more likely to change when the legislator makes a decision that is at odds with its previous image. These are the votes that, according to our logic, legislators should invest the most in explaining to their constituents (Grimmer, 2013). The explanation we propose also helps account for the finding that government decisions can dilute the ideological brand of incumbent parties and lead to their breakdown (Lupu, 2014). The Latin American cases that Lupu studies are examples of parties that apply policies that diverge sharply from their ideological reputations, precisely the scenario where our argument predicts that citizen opinions are most likely to change.

In conclusion, the broad implication of this paper is that voters are responsive to elite behavior in a consistent and predictable way. This is in line with work that has examined the consequences of incumbent actions on voter attitudes other than citizens' perceptions of party positions. The "thermostatic model" that Wlezien and Soroka propose, for instance, suggests that citizens systematically react to incumbent policy decisions by shifting their preferences in the opposite direction (Soroka and Wlezien, 2010; Wlezien, 1995). Similarly consistent reactions have been reported regarding voting behavior: the "policy balancing" literature shows how citizens tend to support parties with opposite policy positions to the 
incumbent in the subsequent election (Alesina and Rosenthal, 1989, 1995; Paldam and Skott, 1995). Hence, our paper contributes to the broader literature that maps the consequences of elite political behavior for mass attitudes.

\section{References}

Adams, James. 2012. "Causes and Electoral Consequences of Party Policy Shifts in Multiparty Elections: Theoretical Results and Empirical Evidence." Annual Review of Political Science 15(1):401-419.

Adams, James, Lawrence Ezrow and Christopher Wleizen. 2016. "The Company you Keep: How Voters Infer Party Positions on European Integration from Governing Coalition Arrangements." American Journal of Political Science 60(4):811-823.

Adams, James, Lawrence Ezrow and Debra Leiter. 2012. "Partisan Sorting and Niche Parties in Europe." West European Politics 35(6):1272-1294.

Adams, James, Lawrence Ezrow and Zeynep Somer-Topcu. 2011. "Is Anybody Listening? Evidence that Voters do not Respond to European Parties' Policy Programmes." American Journal of Political Science 55(2):370-382.

Alesina, Alberto and Howard Rosenthal. 1989. "Partisan Cycles in Congressional Elections and the Macroeconomy." American Political Science Review 83(02):373-398.

Alesina, Alberto and Howard Rosenthal. 1995. Partisan politics, divided government, and the economy. Cambridge: Cambridge University Press.

Allern, Elin Haugsgjerd and Nicholas Aylott. 2009. "Overcoming the fear of commitment: Pre-electoral coalitions in Norway and Sweden." Acta Politica 44(3):259-285.

Armstrong, David A. and Raymond Duch. 2010. "Why can voters anticipate post-election coalition formation likelihoods?" Electoral Studies 29(3):308-315.

Bargsted, Matias A. and Orit Kedar. 2009. "Coalition-Targeted Duvergerian Voting: How 
Expectations Affect Voter Choice under Proportional Representation." American Journal of Political Science 53(2):307-323.

Benoit, Kenneth and Michael Laver. 2012. "The Dimensionality of Political Space: Epistemological and Methodological Considerations." European Union Politics 13(2):194-218.

Benoit, Kenneth, Michael Laver and Slava Mikhaylov. 2009. "Treating Words as Data with Error: Uncertainty in Text Statements of Policy Positions." American Journal of Political Science 53(2):495-513.

Brambor, Thomas, Willam R. Clark and Matt Golder. 2006. "Understanding Interaction Models: Improving Empirical Analyses." Political Analysis 14(1):63-82.

Bräuninger, Thomas. 2005. "A partisan model of government expenditure." Public Choice 125(3-4):409-429.

Clinton, J., S. Jackman and D. Rivers. 2004. "The statistical analysis of roll call data." American Political Science Review 98(02):355-370.

Clinton, Joshua D. 2012. "Using roll call estimates to test models of politics." Annual Review of Political Science 15:79-99.

Cusack, Thomas R. 1997. "Partisan politics and public finance: Changes in public spending in the industrialized democracies, 1955-1989." Public choice 91(3-4):375-395.

Dalton, Russell J. and Ian McAllister. 2015. "Random Walk or Planned Excursion? Continuity and Change in the Left-Right Positions of Political Parties." Comparative Political Studies 48(6):759-787.

Delli Carpini, Michael X. and Scott Keeter. 1996. What Americans Know About Politics and Why it Matters. New Haven: Yale University Press.

Duch, Raymond M., Jeff May and David A. Armstrong. 2010. "Coalition-directed voting in multiparty democracies." American Political Science Review 104(04):698-719.

Falcó-Gimeno, Albert and Ignacio Jurado. 2011. "Minority governments and budget deficits: The role of the opposition." European Journal of Political Economy 27(3):554-565. 
Falcó-Gimeno, Albert and Jordi Muñoz. 2017. "Show Me Your Friends: A Survey Experiment on the Effect of Coalition Signals." The Journal of Politics 79(4):1454-1459.

Fernandez-Vazquez, Pablo. 2014. "And Yet It Moves The Effect of Election Platforms on Party Policy Images." Comparative Political Studies 47(14):1919-1944.

Fortunato, David. 2017. "The Electoral Implications of Coalition Policy-Making." British Journal of Political Science (forthcoming).

Fortunato, David and James Adams. 2015. "How voters' perceptions of junior coalition partners depend on the prime minister's position." European Journal of Political Research $54(3): 601-621$.

Fortunato, David, Nick Lin and Randolph T Stevenson. 2014. Political Knowledge in Coalition Democracies. In Annual Meeting of Midwest Political Science Association.

Fortunato, David and Randolph T. Stevenson. 2013. "Perceptions of Partisan Ideologies: The Effect of Coalition Participation." American Journal of Political Science 57(2):459477.

Gamson, William. 1961. "A Theory of Coalition Formation." American Sociological Review 26(3):373-382.

Glasgow, G, M Golder and S N Golder. 2012. "New empirical strategies for the study of parliamentary government formation." Political Analysis .

Glasgow, Garrett and Sona N. Golder. 2015. "A New Approach to the Study of Parties Entering Government." British Journal of Political Science 45(4):739-754.

Grimmer, Justin. 2013. Representational Style in Congress: What Legislators Say and Why It Matters. Cambridge University Press.

Grynaviski, Jeffrey D. 2010. Partisan Bonds: Political Reputations and Legislative Accountability. New York: Cambridge University Press.

Harbridge, Laurel and Neil Malhotra. 2011. "Electoral Incentives and Partisan Conflict in Congress: Evidence from Survey Experiments." American Journal of Political Science $55(3): 494-510$. 
Hetherington, Marc J. 2001. "Resurgent Mass Partisanship: The Role of Elite Polarization." American Political Science Review 95(3):619-31.

Indridason, Indridi H. 2011. "Coalition Formation and Polarisation." European Journal of Political Research 50(5):689-718.

Iversen, Torben and David Soskice. 2006. "Electoral Institutions and the Politics of Coalition: Why Some Democracies Redistribute More Than Others." American Political Science Review 100(2):165-181.

Klingemann, Hans-Dieter, Richard I. Hofferbert and Ian Budge. 1994. Parties, policies, and democracy. Boulder, CO: Westview.

Lachat, Romain. 2008. "The Impact of Party Polarization on Ideological Voting." Electoral Studies 27(4):687-698.

Lederer, Wolfgang and Helmut Küchenhoff. 2006. "A Short Introduction to the SIMEX and MCSIMEX." The Newsletter of the R Project 6(4):26.

Levendusky, Matthew. 2009. The partisan sort: How liberals became Democrats and conservatives became Republicans. University of Chicago Press.

Lupu, Noam. 2014. "Brand Dilution and the Breakdown of Political Parties in Latin America." World Politics 66(4):561-602.

Martin, Lanny W. and Randolph T. Stevenson. 2001. "Government formation in parliamentary democracies." American Journal of Political Science 45(1):33-50.

Müller, Wolfgang C. and Kaare M. Strøm. 1999. Policy, office, or votes?: how political parties in Western Europe make hard decisions. Cambridge: Cambridge University Press.

Nannestad, Peter and Martin Paldam. 2003. The cost of ruling. In Economic Voting, ed. Michael Taylor Hans Dorussen. Routledge.

Paldam, Martin and Peter Skott. 1995. "A rational-voter explanation of the cost of ruling." Public Choice 83(1-2):159-172.

Poole, K.T. and H. Rosenthal. 2007. Ideology and Congress. Transaction Publishers.

Powell, Jr, G Bingham and Guy D Whitten. 1993. "A Cross-National Analysis of Economic 
Voting: Taking Account of the Political Context." American Journal of Political Science 37(2):391-414.

Prior, Markus. 2005. "News vs. Entertainment: How Increasing Media Choice Widens Gaps in Political Knowledge and Turnout." American Journal of Political Science 49(3):577592.

Prior, Markus. 2007. Post-broadcast democracy: How media choice increases inequality in political involvement and polarizes elections. Cambridge University Press.

Sagarzazu, Iñaki and Heike Klüver. 2017. "Coalition governments and party competition: Political communication strategies of coalition parties." Political Science Research and Methods 5(2):333-349.

Singh, Shane P and Judd R Thornton. 2016. "Strange Bedfellows: Coalition Makeup and Perceptions of Democratic Performance among Electoral Winners." Electoral Studies 42:114125.

Soroka, Stuart N. and Christopher. Wlezien. 2010. Degrees of Democracy: Politics, Public Opinion, and Policy. Cambridge University Press.

Spoon, Jae-Jae and Heike Klüver. 2016. "Does anybody notice? How policy positions of coalition parties are perceived by voters." European Journal of Political Research 56(1):115132.

Stevenson, Randolph T. 2002. "The cost of ruling, cabinet duration, and the "median-gap" model." Public Choice 113(1-2):157-178.

Tavits, Margit. 2007. "Clarity of responsibility and corruption." American Journal of Political Science 51(1):218-229.

Van der Eijk, Cees, Hermann Schmitt and Tanja Binder. 2005. Left-right Orientations and Party Choice. In The European voter. A comparative study of modern democracies, ed. Jacques Thomassen. Oxford University Press pp. 167-191.

Wlezien, Christopher. 1995. "The public as thermostat: Dynamics of preferences for spending." American Journal of Political Science pp. 981-1000. 
Zaller, John R. 1992. The Nature and Origins of Mass Opinion. Cambridge University Press. 


\section{Supporting Information}

\section{A Supporting Information for the Cross-Country Test}

\section{Aggregated Data Descriptive Statistics}

Table A1 provides the descriptive statistics employed in the cross-national analyses. On average the parties of our sample are centrist and voters' perception over their left-right shifts around .3 absolute points, on average. These changes are by and large balanced toward the right and toward the left -i.e. the mean shift is very close to zero--. Governments formed are on average between .27 (where the position of the government is weighted by the members' seatshare) and .11 (unweighted) points to the right of the parties in our sample, while the average distance in absolute terms is between 2.28 (weighted) and 2.24 (unweighted). Finally, according to our classifications, the situations in which government parties had a closer alternative than the one they chose happen no less than $50 \%$ of the times.

Table A1: Descriptive Statistics

\begin{tabular}{rccc}
\hline \hline & Mean/Prop. & Median & S.D. \\
\hline All parties & & & \\
Party Status (In Government=1) & 0.29 & 0 & 0.45 \\
Position $_{t+1}$ & 5.14 & 5.52 & 2.26 \\
Update & -0.01 & -0.05 & 0.39 \\
Update (abs) & 0.30 & 0.25 & 0.25 \\
Distance $_{R G}$ (weighted) & 0.27 & 0.00 & 2.86 \\
Distance $_{R G}($ unweighted) & 0.11 & 0.00 & 2.81 \\
Distance $_{R G}($ weighted - abs) & 2.28 & 2.08 & 1.73 \\
Distance \\
(unweighted - abs) & 2.24 & 2.09 & 1.69 \\
Government parties & & & \\
Alternative (prob. model - With=1) & 0.73 & 1 & 0.45 \\
Alternative (MWC - With=1) & 0.50 & 0.50 & 0.50 \\
\hline \hline
\end{tabular}


Regression Output for the Empirical Model in the Main Text

Table A2 presents the results of estimating the regression equation that analyzes the impact of coalition entry on a party's perceived left-right placement (Equation 1).

Table A2: Regression results for the empirical model in the main text (Equation 1).

\begin{tabular}{lc}
\hline \hline & DV: Update \\
\hline Distance $_{\mathrm{RG}}$ & -0.07 \\
& $(0.05)$ \\
Party Status & 0.05 \\
& $(0.16)$ \\
Distance $_{\mathrm{RG}} *$ Party Status & -0.05 \\
& $(0.18)$ \\
Alternative & -0.04 \\
Distance $_{\mathrm{RG}} *$ Alternative & $(0.21)$ \\
& 0.09 \\
Distance $_{\mathrm{RG}} *$ Party Status & $(0.05)$ \\
& -0.04 \\
Distance $_{\mathrm{RG}} *$ Party Status $*$ Alternative & $(0.20)$ \\
& 0.19 \\
Intercept & $(0.19)$ \\
& -0.04 \\
Country Fixed Effects & $(0.21)$ \\
$\mathrm{R}^{2}$ & $\mathrm{YES}$ \\
\hline \hline
\end{tabular}

Dependent variable: The change in the party's average left-right placement. Positive values indicate a shift to the right, and vice versa. Country fixed effects and clustered standard errors.

Evidence from Aggregated Data at the Party Level: Calculating the Overall Coalition Position as the Arithmetic Mean

The empirical analysis in the main text computes the ideological position of each potential government as the seat-weighted average of the position of each party in the cabinet. This 
application of Gamson's Law implies that larger parties contribute more to the overall coalition position than smaller parties. Hence, using this operationalization might imply that it is more likely for smaller parties to be coded as having an ideologically closer viable alternative $($ Alternative $=1)$. In this regard, recent work has shown that coalition participation has a stronger effect on the image of junior partners than on senior ones (Fortunato and Adams, 2015). Also, others have found that voters tend to attribute a disproportionate influence to minor coalition partners in estimating the relative influence of coalition members on policy-making (Bowler et al., 2016).

To address this potential source of bias, we provide an additional test of our argument using a different coding approach: in this robustness check, the overall coalition position is defined as the unweighted average of the left-right placement of all coalition partners. Hence, both small and large parties contribute equally to the government's position. With this alternative operationalization, we re-estimate the model in Equation 1. Figure A1 presents the predicted shifts with and without an ideologically closer alternative coalition.

The results of this robustness check confirm the pattern reported in the main text. If the party joins the coalition that voters perceive to be the ideologically closest option (left plot), entering the cabinet does not significantly change the party's left-right reputation. Voters' perceptions of the party barely shift and, to the extent that they do, they do so in the opposite direction: joining a more conservative cabinet shifts the placement to the left and vice versa. On the contrary, if there was a viable alternative that voters perceived to be a more ideologically consistent choice (right plot), then the party's decision changes voter opinions substantially and in the expected direction.

\section{Evidence from Aggregated Data at the Party Level: Minimal-Winning Coali- tions as the Viable Alternatives}

This section further expands the cross-country analysis of the impact of coalition membership on a party's left-right image. It reports the results of a robustness test in which we 
Figure A1: Predicted change in a party's left-right reputation after joining the government. 95\% Confidence Intervals. Robustness check: The overall government position is defined as the unweighted mean.
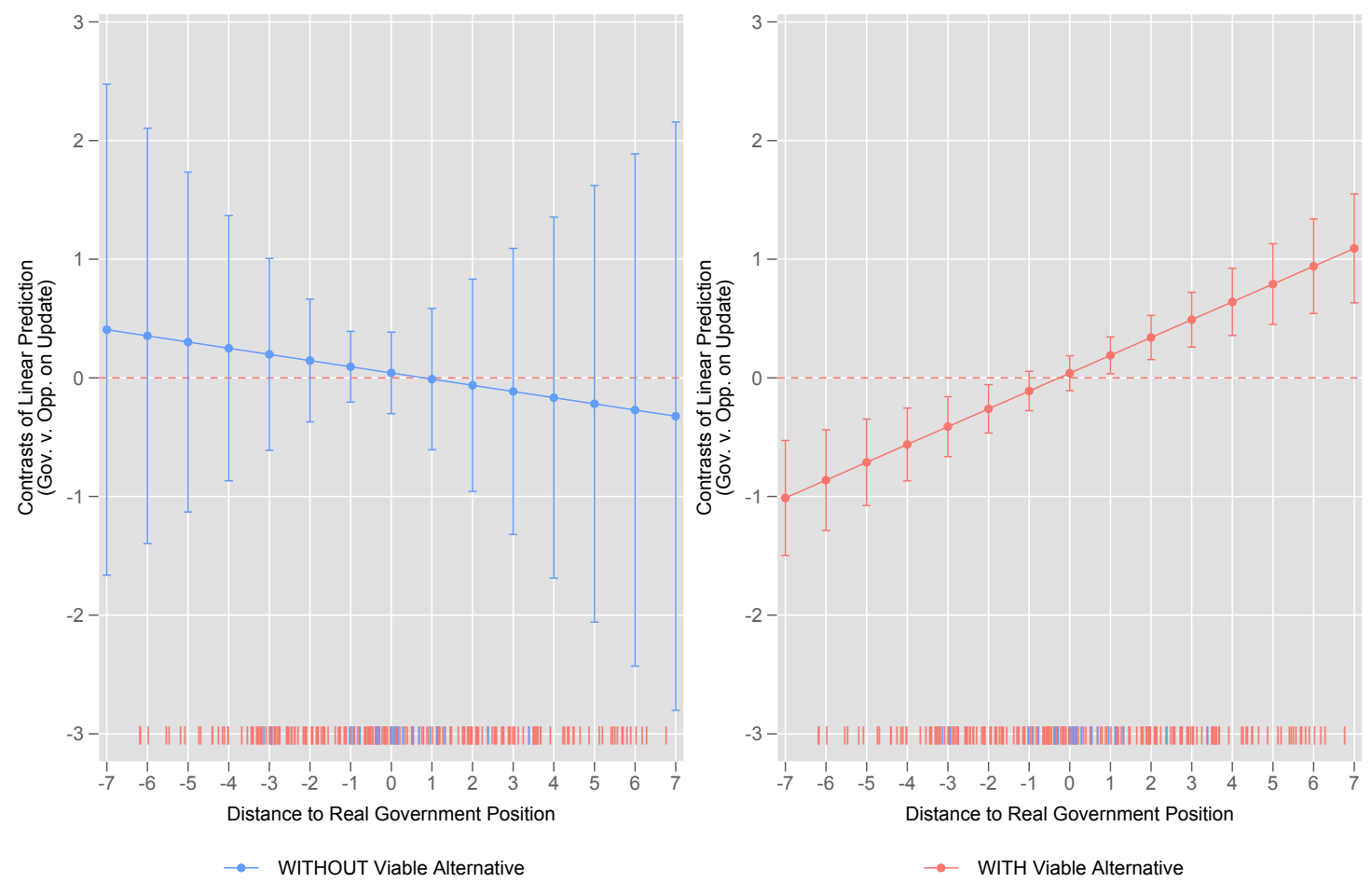

NOTE: The left plot displays the predicted shift in the average left-right placement for a party that confirms voters' priors by choosing the coalition that was perceived to be ideologically closest among the viable alternatives. The right plot refers to a party whose choice is at odds with voters priors. The horizontal axes indicate the left-right distance between the coalition that forms and the focal party.

adopt an alternative definition of what constitutes a viable potential government. Instead of estimating a model of government formation and selecting the potential governments with the highest likelihood of materializing, here we adopt a purely arithmetic criterion: We define as viable any potential government that qualifies as a minimal winning coalition (MWC). ${ }^{30}$ Now the variable Alternative takes the value of 1 if voters consider that the party could have joined a minimal winning coalition that is ideologically closer to the party than the coalition

\footnotetext{
${ }^{30}$ We identify the set of MWC using the following procedure. First, we take the parliamentary composition resulting from elections using the ParlGov dataset compiled by Döring and Manow (2011). We then compute all the possible Minimal Winning Coalitions that could potentially form in each parliament. For that purpose we used the "Indices of Power IOP 2.0" software (Bräuninger and König, 2005). Table A3 lists the number of MWC in each country-year.
} 
that the party actually entered. With this alternative operationalization we re-estimate the model in Equation 1.

The results are presented in Figure A2. It plots the predicted shift in the party's left-right image as a result of entering the government, depending on whether the coalition that the party joins is the one voters considered to be the most ideologically congruent choice. The left-hand plot reports predicted changes when the party chooses the coalition that voters expected. The right-hand one, in turn, refers to the scenario in which the party's decision is at odds with voters' priors. The horizontal axis indicates the ideological distance between the party and the government that forms, where positive values indicate that the government is perceived to be more right-wing than the party. The vertical axis, in turn, reflects the predicted shift in the party's average left-right placement.

Using this alternative definition of viable government does not substantially affect the empirical results. Much like the evidence presented in the main text (Figure 1), Figure A2 suggests that, when the party's choice confirms voters' priors, joining the government does not alter voter perceptions of the party's ideology. The predicted shift is very small and it is not statistically different from zero. In contrast, if the party had the opportunity to form an alternative government that voters considered to be more ideologically similar, the party's decision makes voters shift their perceptions substantially. 
Figure A2: Predicted change in a party's left-right reputation after joining the government. 95\% Confidence Intervals. Robustness check: Minimal winning coalitions as the set of viable governments.
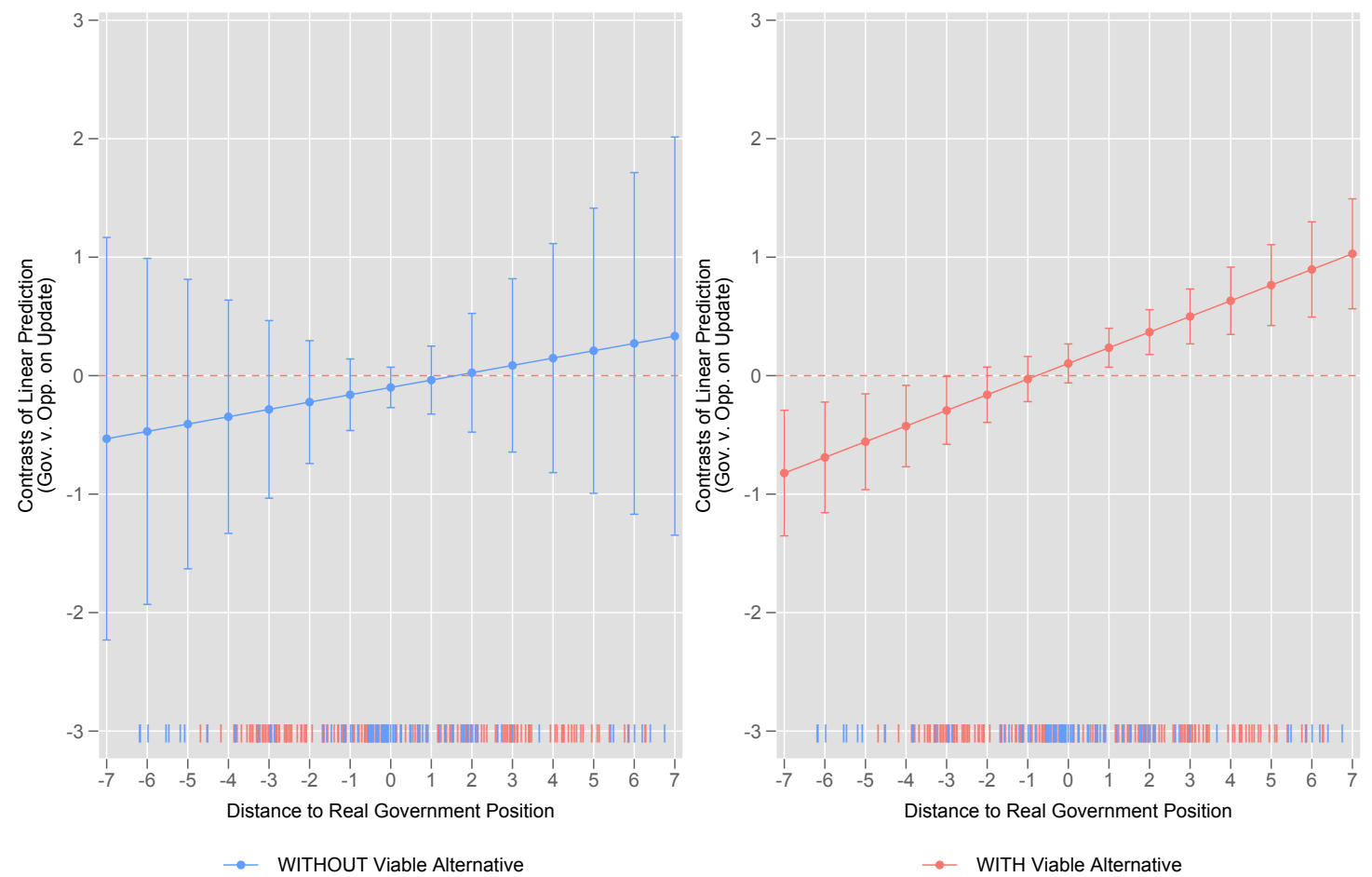

NOTE: The left plot displays the predicted shift in the average left-right placement for a party that confirms voters' priors by choosing the coalition that was perceived to be ideologically closest among the viable alternatives. The right plot refers to a party whose choice is at odds with voters priors. The horizontal axes indicate the left-right distance between the coalition that forms and the focal party. 
Table A3: Descriptive Statistics on Minimal Winning Coalitions

\begin{tabular}{lccc}
\hline \hline Country & Year & N. MWC & N. Parties \\
\hline Denmark & 1994 & 33 & 4.45 \\
Denmark & 1998 & 95 & 5.52 \\
Denmark & 2001 & 24 & 4.38 \\
Denmark & 2005 & 20 & 4.00 \\
Denmark & 2007 & 23 & 4.17 \\
Denmark & 2011 & 55 & 5.18 \\
Germany & 1998 & 4 & 2.25 \\
Germany & 2002 & 3 & 2.00 \\
Germany & 2005 & 7 & 2.86 \\
Germany & 2009 & 4 & 2.25 \\
Netherlands & 1981 & 24 & 4.38 \\
Netherlands & 1982 & 3 & 2.00 \\
Netherlands & 1986 & 3 & 2.00 \\
Netherlands & 1989 & 10 & 4.00 \\
Netherlands & 1994 & 115 & 5.80 \\
Netherlands & 1998 & 17 & 4.00 \\
Netherlands & 2002 & 33 & 4.45 \\
Netherlands & 2003 & 13 & 3.69 \\
Netherlands & 2006 & 42 & 4.57 \\
Netherlands & 2010 & 40 & 4.53 \\
Norway & 1977 & 6 & 2.50 \\
Norway & 1981 & 7 & 3.00 \\
Norway & 1985 & 6 & 2.83 \\
Norway & 1989 & 8 & 3.13 \\
Norway & 1993 & 8 & 3.13 \\
Norway & 1997 & 8 & 3.38 \\
Norway & 2001 & 12 & 3.17 \\
Norway & 2005 & 14 & 3.50 \\
Norway & 2009 & 8 & 3.13 \\
Sweden & 1979 & 4 & 2.25 \\
Sweden & 1982 & 5 & 2.40 \\
Sweden & 1985 & 5 & 2.40 \\
Sweden & 1988 & 6 & 2.50 \\
Sweden & 1991 & 16 & 3.56 \\
Sweden & 1994 & 7 & 2.57 \\
Sweden & 1998 & 14 & 3.50 \\
Sweden & 2002 & 9 & 3.38 \\
Sweden & 2006 & 13 & \\
\hline \hline
\end{tabular}

NOTE: The first column indicates the country and the second reports the year in which the parliamentary election takes place. Next, the third column refers to the number of minimal winning coalitions that result from the outcome of the parliamentary election. Lastly, the fourth column provides the effective number of parliamentary parties. 


\section{Evidence from Aggregated Data at the Party Level: Model in Levels.}

We also examine whether the empirical pattern reported in the main text holds once we adopt a different definition of the outcome variable. Here we estimate a model in levels, i.e. an equation in which the dependent variable is defined as the party's average placement. Specifically, we estimate the following regression model:

$$
\begin{aligned}
& \text { Position }_{\mathrm{t}+1}=\alpha+\beta_{1} \text { Position }_{\mathrm{t}}+\beta_{2} \text { Position }_{\mathrm{RG}}+\beta_{3} \text { Party Status }+\beta_{4} \text { Alternative } \\
& +\beta_{5} \text { Party Status } * \text { Alternative } \\
& +\beta_{6} \text { Distance }_{\mathrm{RG}} * \text { Party Status } \\
& +\beta_{7} \text { Distance }_{\mathrm{RG}} * \text { Alternative } \\
& +\beta_{8} \text { Distance }_{\mathrm{RG}} * \text { Party Status } * \text { Alternative } \\
& +\beta_{9} \text { Distance }_{\mathrm{RG}} * \text { Party Status } \\
& +\beta_{10} \text { Distance }_{\mathrm{RG}} * \text { Alternative } \\
& +\beta_{11} \text { Distance }_{\mathrm{RG}} * \text { Party Status } * \text { Alternative }
\end{aligned}
$$

This equation defines the party's perceived left-right after the government forms, Position $_{\mathrm{t}+1}$, as a function of the previous placement, Position $_{t}$, and whether the party joins the cabinet or not, Party Status. To identify how the effect of joining the cabinet varies depending on the overall government position and whether the party has an ideologically closer viable alternative, both variables are interacted with Distance $_{\mathrm{RG}}$ and Alternative. Two triple interactions are then specified to account for how the position of the government and the available of closer alternatives modulate the impact of each other.

Figure A3 presents the predicted effect of joining the government on the party's average left-right placement. The left plot refers to the context where the party chooses the coalition that voters considered to be the ideologically closest option. The right-hand plot, in turn, reports results when the party does not choose the coalition that voters perceived to be the 
most ideologically congruent option.

Figure A3: Predicted change in a party's left-right reputation after joining the government. 95\% Confidence Intervals. Robustness check: Dependent variable as the average placement after the government formation.
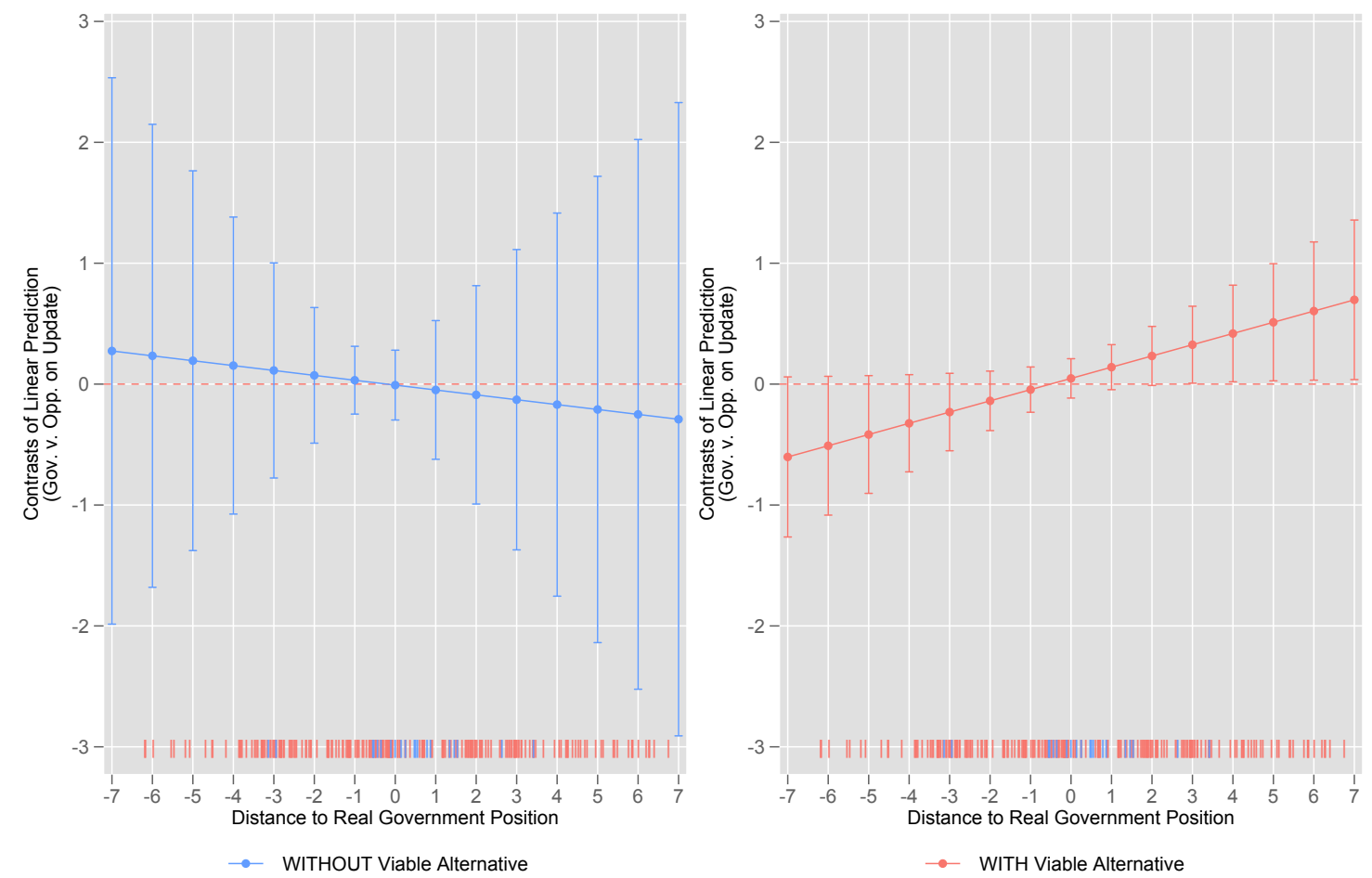

NOTE: The left plot displays the predicted shift in the average left-right placement for a party that confirms voters' priors by choosing the coalition that was perceived to be ideologically closest among the viable alternatives. The right plot refers to a party whose choice is at odds with voters priors. The horizontal axes indicate the left-right distance between the coalition that forms and the focal party.

The results of this robustness test also confirm the empirical finding reported in the main text. Coalition membership is not consequential if the party's action confirms voters' priors. The effect of joining the cabinet is very small, in the opposite direction, and it is not distinguishable from zero. In contrast, as the plot on the right indicates, when the party's action is at odds with voters' priors it significantly changes voter perceptions. Hence, we can conclude that the empirical pattern is not an artifact of choosing a model in either levels or in first differences. 


\section{Taking Into Account Uncertainty in Measurement}

This section addresses the possibility that the cross-country findings presented in the main text are driven by uncertainty in the measurement of party reputations. Indeed, both the dependent variable, Update, and a key independent variable, Distance (Equation 1), are affected by measurement error because both indicators rely on average responses to survey questions. A potential consequence of uncertainty in measurement is attenuation bias in regression estimates (Carroll et al., 1995).

In order to confirm that our findings are not an artifact of measurement error, we implement a simulation-extrapolation strategy (Lederer and Küchenhoff, 2006; Benoit et al., 2009). This approach simulates the effect of measurement error on regression results and extrapolates the estimates that would be obtained if variables were measured without noise. To do so, we incorporate into the analysis estimates of the uncertainty in the measurement of the variables Update and Distance. We obtain these estimates by leveraging the fact that both indicators are based on average survey responses to questions about the left-right position of political parties and we use the standard error of these averages to characterize the magnitude of measurement uncertainty. This is the same logic employed by (Benoit et al., 2009). With these measurement error estimates, we apply the simulation-extrapolation approach to Equation 1:

$$
\begin{aligned}
\text { Update }=\beta_{1} & +\beta_{2} \text { Distance }_{\mathrm{RG}}+\beta_{3} \text { Party Status }+\beta_{4} \text { Alternative } \\
& +\beta_{5}{\text { Party } \text { Status } * \text { Alternative }} \\
& +\beta_{6} \text { Distance }_{\mathrm{RG}} * \text { Party Status } \\
& +\beta_{7} \text { Distance }_{\mathrm{RG}} * \text { Alternative } \\
& +\beta_{8} \text { Distance }_{\mathrm{RG}} * \text { Party Status } * \text { Alternative }
\end{aligned}
$$

Table A4 provides full regression results. To facilitate the interpretation of the regression estimates, Figure A4 presents the predicted change in the average perceived position of the 
party as a function of the distance with the coalition it joins. This figure compares two scenarios: The left plot presents the change in average perceptions when the party joins the coalition that voters perceived to be the most ideologically consistent choice (Alternative $=0)$. The right plot, in turn, refers to the predicted change when voters considered that the party had an ideologically closer alternative (Alternative $=1$ ). The predicted changes are consistent with our argument and replicate the findings presented in the main text (Figure 1). Namely, when the party had no ideologically closer alternative, joining the coalition shifts voters perceptions only slightly, in the opposite direction, and this change is not statistically distinguishable from zero. In contrast, when voters think that the party had an ideologically closer alternative coalition, the choice of cabinet partners moves voters' perceptions in the expected direction, and this shift is statistically significant. Hence, we can conclude that the empirical pattern reported in this paper is not an artifact of measurement error in covariates. 
Figure A4: Predicted change in a party's left-right reputation after joining the government. 95\% Confidence Intervals. Simulation-Extrapolation estimates

There is No Ideologically Closer Alternative Coalition

Alternative $=0$

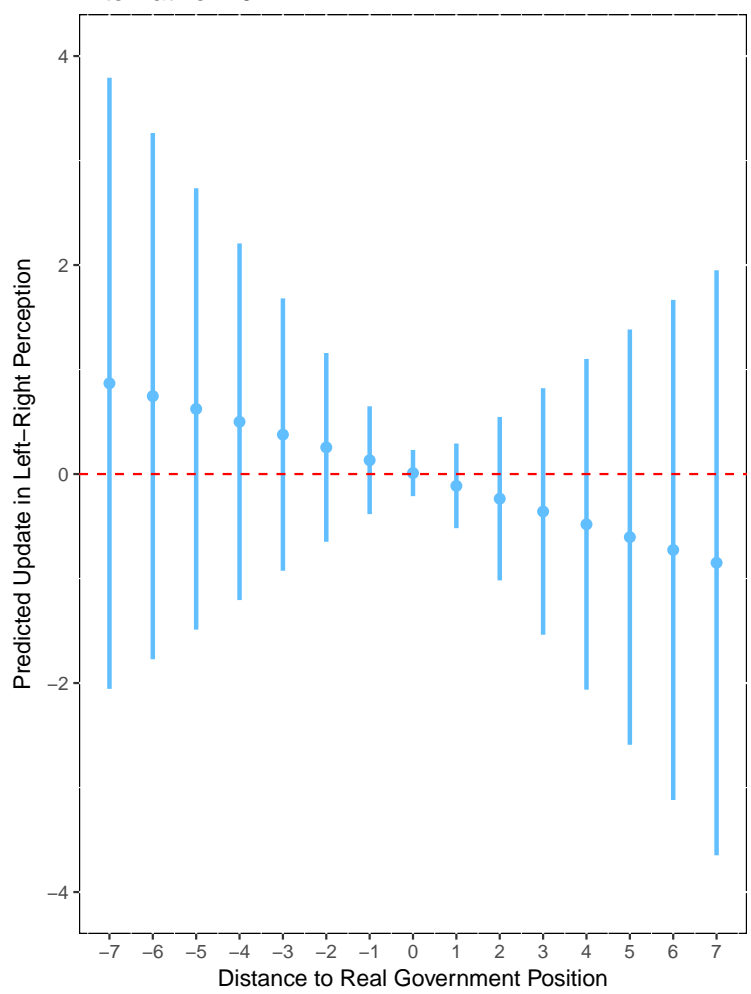

There is Ideologically Closer Alternative Coalition

Alternative $=1$

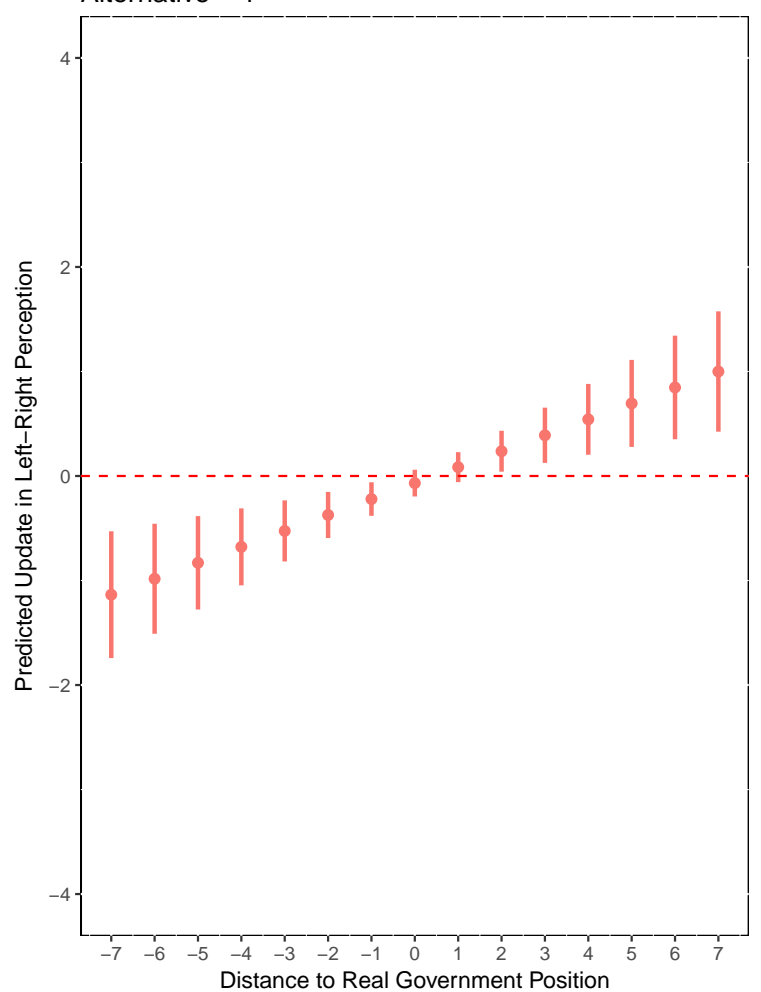

NOTE: The left plot displays the predicted shift in the average left-right placement for a party that confirms voters' priors by choosing the coalition that was perceived to be ideologically closest among the viable alternatives. The right plot refers to a party whose choice is at odds with voters priors. The horizontal axes indicate the left-right distance between the coalition that forms and the focal party. 
Table A4: Regression results for the empirical model in the main text (Equation 1). Simulation-Extrapolation estimates

\begin{tabular}{lc}
\hline \hline & DV: Update \\
\hline Distance $_{\mathrm{RG}}$ & -0.04 \\
& $(0.07)$ \\
Party Status & 0.01 \\
& $(0.17)$ \\
Alternative & -0.07 \\
& $(0.15)$ \\
Alternative $*$ Party Status & -0.01 \\
& $(0.18)$ \\
Distance $_{\mathrm{RG}} *$ Alternative & 0.06 \\
& $(0.07)$ \\
Distance $_{\mathrm{RG}} *$ Party Status & -0.08 \\
& $(0.22)$ \\
Distance & $\mathrm{RG} *$ Party Status $*$ Alternative \\
& 0.22 \\
Intercept & $(0.23)$ \\
& -0.01 \\
Country Fixed Effects $_{\mathrm{N}}$ & $(0.16)$ \\
$\mathrm{R}^{2}$ & $\mathrm{YES}$ \\
\hline \hline
\end{tabular}

Dependent variable: The change in the party's average left-right placement. Positive values indicate a shift to the right, and vice versa. Simulation-extrapolation coefficient estimates with jacknife standard errors. Country fixed effects. 


\section{B Supporting Information for the Test with Norwe- gian Individual Panel Data}

\section{Additional Graph to Illustrate the Results}

We here show an alternative way to illustrate the results reported in Figure 2 and Table 3 in the main text. We compare the distribution of changes in opinions about the Sp across two groups of respondents: Figure B1 shows that those voters for whom the Sp's choice was consistent with its left-right placement did not change their beliefs about the party: The distribution is an almost symmetrical blue bell curve with a zero mean. In contrast, the distribution in red shows that those who thought that the Sp was closer to the center-right parties adjusted their opinions about the party towards the left.

Figure B1: Distribution of changes in perceptions of the Norwegian Center Party's (Sp) left-right position. In blue, opinion changes among respondents who had thought that the (left-leaning) coalition that formed was the ideologically closest option. In red, shifts among those who had considered the right-leaning alternative coalition to be a more ideologically consistent choice.

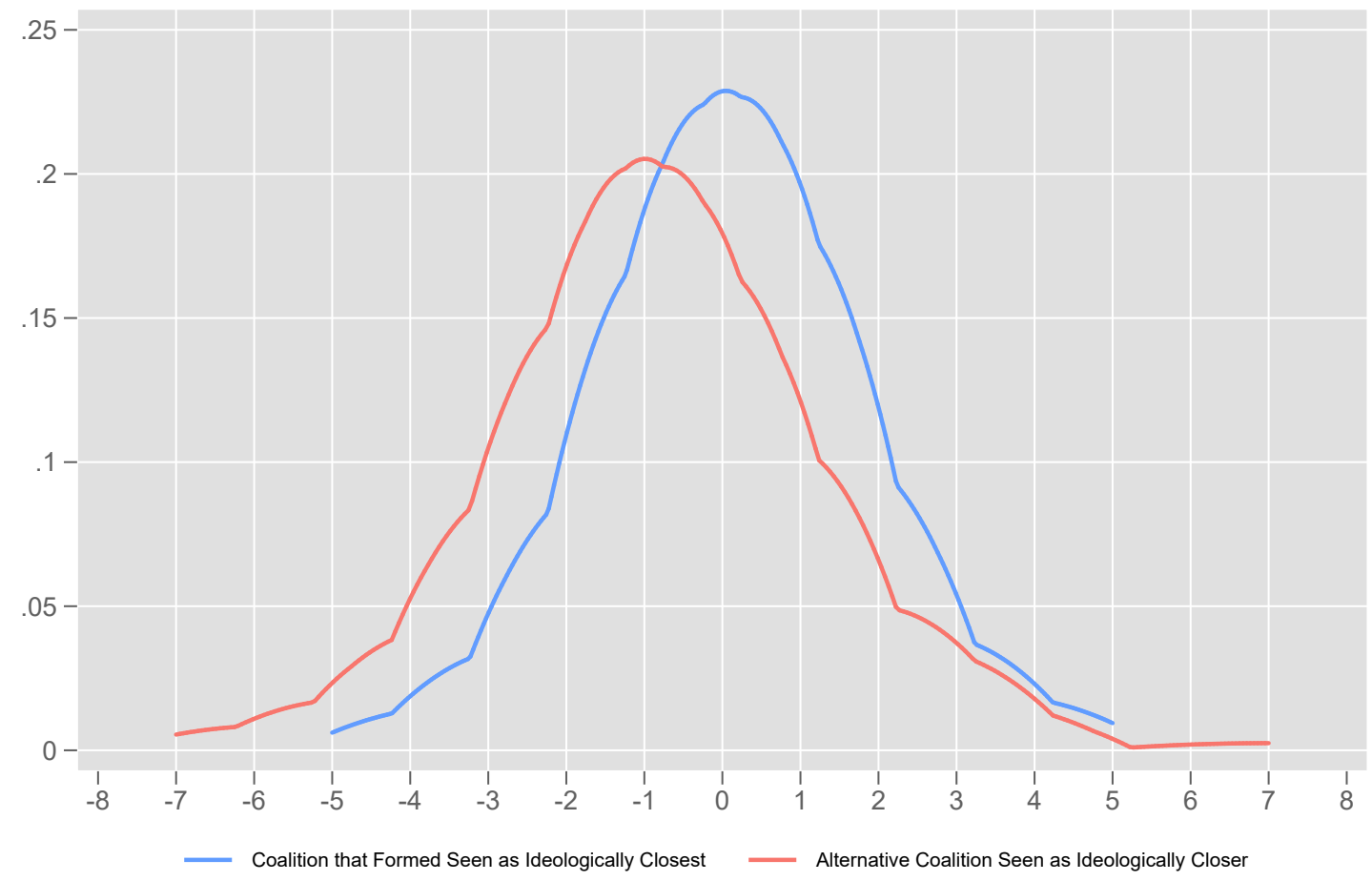




\section{Addressing Alternative Explanations}

We here address several alternative explanations to the evidence presented in the main text using the Norwegian panel data. First, it could be argued that the difference in updating between groups is a mechanical consequence of the fact that respondents who considered that the right-leaning coalition was the most ideologically consistent choice for the Center Party (Sp) also tended to place this party closer to conservative positions. One version of this alternative explanation posits that such difference in initial beliefs coupled with completely random updates in perceptions can yield the same pattern that we report in this paper. The following Monte Carlo simulation, however, shows that this is not likely to be the case.

This simulation is based on a stylized representation of the Norwegian party system in 2005. A set of citizens have opinions about the ideological position of 5 political parties: two on the left, two on the right, and a centrist one. Individual perceptions are random draws from five normal distributions with location parameters $2,3,7,8$, and 5 , respectively. The centrist party is pivotal in the formation of either of two viable coalitions: one with the parties on the left, and another with the parties on the right. Citizens are split in two groups according to whether they initially perceive the centrist party to be closer to the right coalition or the left-leaning coalition. Perceptions about the centrist party after the coalition forms are a new draw from the same normal distribution with a mean of five.

We run fifty thousand simulations of this updating process. The source code is available in Figure B3. Figure B2 plots the distribution of average initial and final perceptions about the centrist party for each group. It shows that each group undergoes a change in opinions of the same magnitude but opposite directions. In other words, this updating process generates a regression to the mean pattern. Hence, it cannot account for the evidence we provide in this paper, i.e. that the formation of a left-leaning coalition only changes the perception of those respondents who thought initially that the conservative coalition was a more ideologically consistent option. 
Figure B2: Monte Carlo simulation. Distribution of average perceptions about the ideological position of the centrist party before and after the coalition forms. Main assumption: Post coalition perceptions are an independent draw from the same normal distribution.

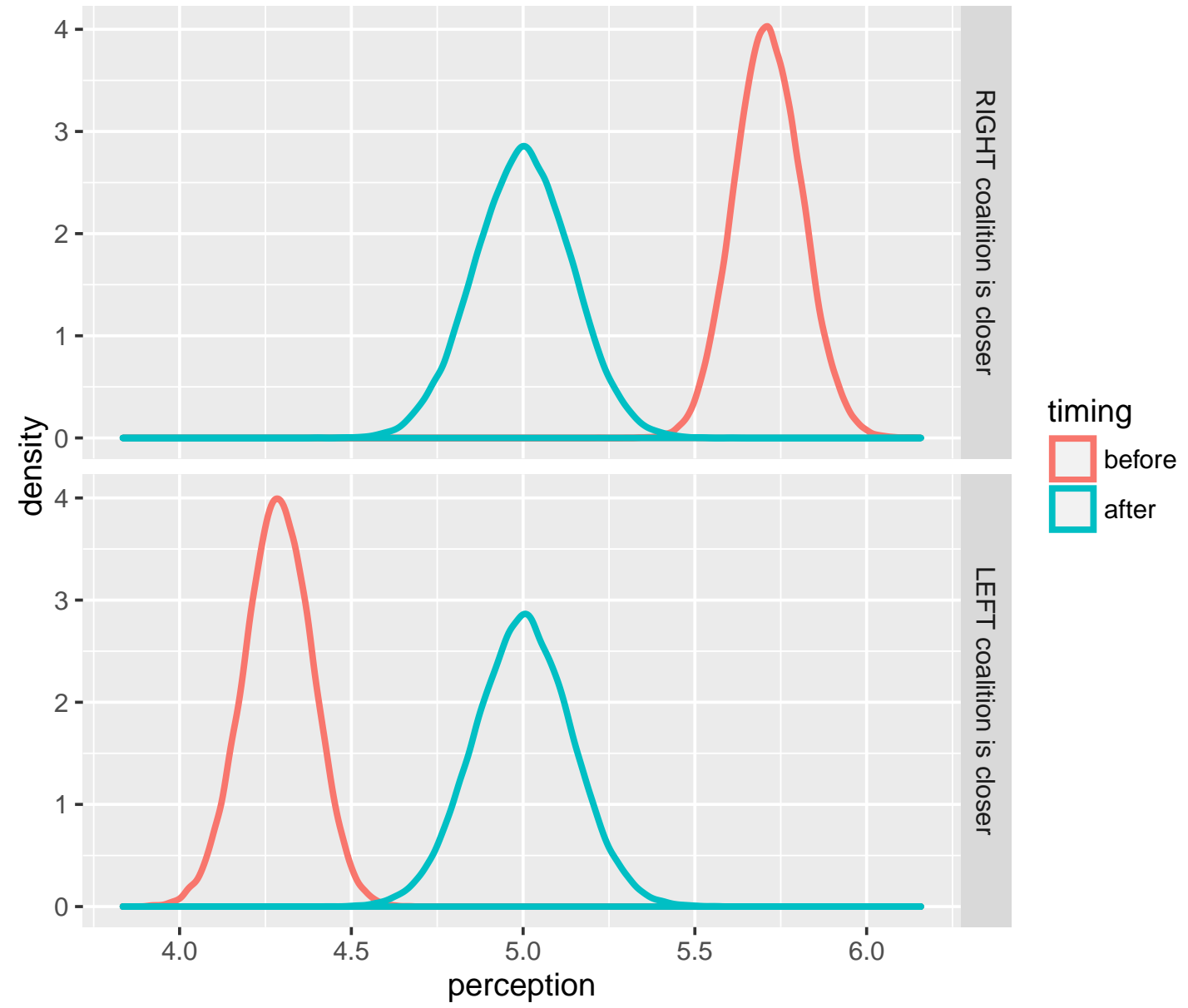

NOTE: The top panel refers to opinions of citizens who consider that the Sp party is closer to the rightleaning coalition. The bottom panel reports results for those who consider the left-leaning cabinet as the most ideologically consistent choice.

We now examine another version of the argument that the pattern we find in this paper is an artifact of the heterogeneity in initial perceptions about the Center Party (Sp). It contends that the larger shift in perceptions for those who perceived the conservative coalition to be ideologically closer stems from the higher distance between the initial perception about the Sp and the position of the left-leaning coalition that actually formed. Accordingly, it would be the ex ante opinion about the party rather than the perceived closeness to each of the two potential coalitions what would be driving the variation of our dependent variable. We 
Figure B3: R code employed to run the Monte Carlo simulation.

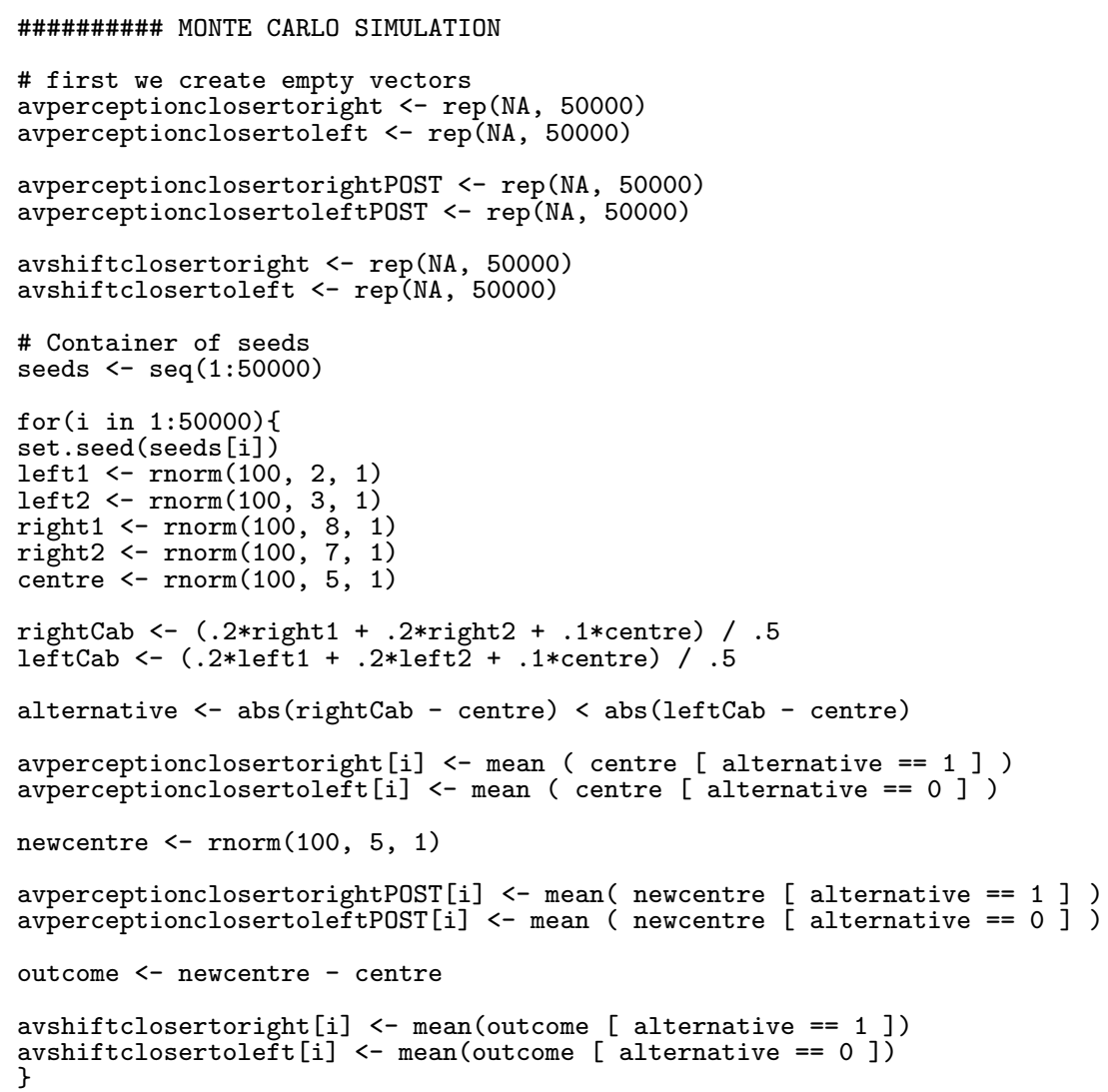

control for this possibility using the same strategy we followed in the aggregate analysis (Equation 1).

In Table B1 we present the results of an OLS regression analysis where we estimate the change in perceptions about the $\mathrm{Sp}$ as a function of whether the individual perceives that the right-leaning alternative coalition was ideologically closer to the Sp. This is captured by the variable Alternative. We also include the variable Distance $_{R G-S p}$ which measures the perceived ideological distance between the coalition that formed and the Sp party. Both variables are interacted as in Equation 1. Similarly, in order to take into account potential ceiling or floor effects, we control for the position attributed to the Sp at time $t$. Also, the model includes ideological and socio-demographic variables such as respondents' level of education and age group, which may be a proxy for political sophistication and experience. 
Table B1: Update in perceptions about the Center Party as a function of whether the individual thought that the party has joined the most ideologically congruent option or not (Alternative).

\begin{tabular}{rcccc}
\hline \hline & $(1)$ & $(2)$ & $(3)$ & $(4)$ \\
\hline Alternative & $-0.89^{*}$ & $0.30^{*}$ & 0.25 & 0.27 \\
& {$[0.16]$} & {$[0.14]$} & {$[0.14]$} & {$[0.14]$} \\
Distance $_{\text {RG-Sp }}$ & & -0.09 & -0.07 & -0.07 \\
& & {$[0.05]$} & {$[0.05]$} & {$[0.05]$} \\
Distance $_{\text {RG-Sp }}{ }^{*}$ Alternative & & $0.18^{*}$ & $0.17^{*}$ & $0.17^{*}$ \\
& & {$[0.06]$} & {$[0.06]$} & {$[0.06]$} \\
Constant & 0.09 & $3.47^{*}$ & $3.77^{*}$ & $3.64^{*}$ \\
& {$[0.07]$} & {$[0.20]$} & {$[0.25]$} & {$[0.38]$} \\
L-R Sp Perception & no & yes & yes & yes \\
L-R Self Placement & no & no & yes & yes \\
Level of Education & no & no & no & yes \\
Age Group & no & no & no & yes \\
& & & & \\
$\mathrm{N}$ & 682 & 682 & 677 & 677 \\
$\mathrm{R}^{2}$ & 0.04 & 0.43 & 0.44 & 0.45 \\
& & & & \\
\hline \hline
\end{tabular}

Standard errors in brackets

$* \mathrm{p}<0.05$

Column 1 offers the results of a bivariate regression model that confirms our previous findings. Perceiving that the Sp was closer to the right-leaning coalition than to the leftleaning option it actually joined (Alternative $=1$ ) leads voters to shift their perception of the Sp to the left. The interaction term in models 2 to 4 shows that the effect of joining the cabinet is different between the group of voters who thought that the center-left coalition was the ideologically closest choice $($ Alternative $=0$ ) and those who thought that the Sp was closer to the center-right alternative (Alternative=1). In line with our argument, the effect of Distance is almost zero in the former case. However, for the latter, perceptions shift to the left (i.e. negative values) for each Distance score. 
Figure B4 graphs the the predicted effect of Distance $_{R G-S p}$ using the estimates in model 4. It shows that only the respondents who perceived the left coalition to be to the right of the Sp that the variable Alternative makes no difference. For the rest, the group of respondents that updates the perception of the Sp position towards the left-leaning coalition are those who had considered that the party was closer to the center-right coalition.

Figure B4: Prediction at Representative Values with 95\% Confidence Intervals.

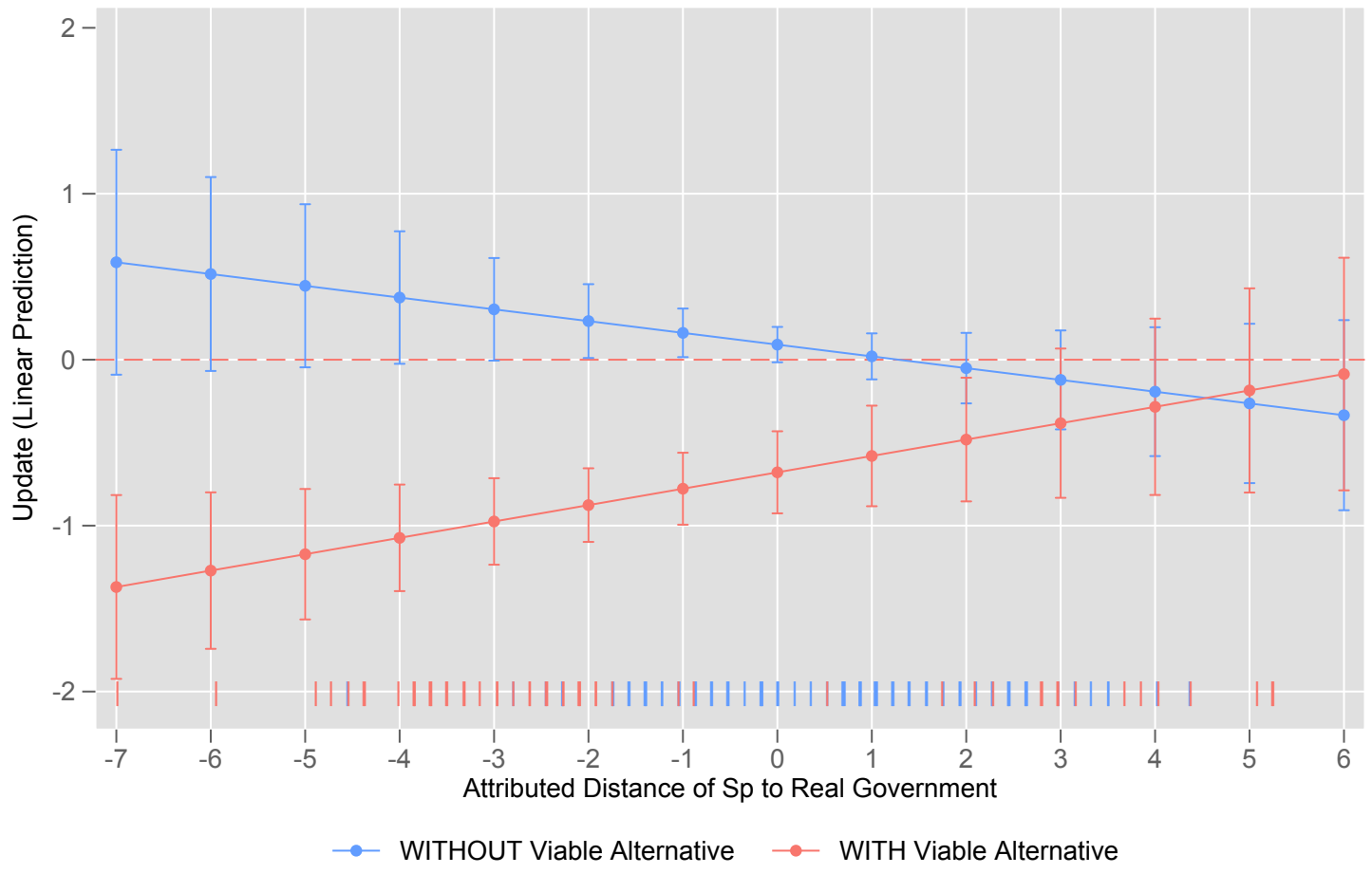

As a further robustness check, we relax the linearity assumption in the previous regression model. We show the results of a local polynomial regression predicting the update in perceptions of the Sp. It is modeled as a function of the perceived distance to the leftleaning coalition for the two relevant groups of voters (with and without perceived closer Alternative). Figure B5 presents a kernel-weighted local polynomial smooth plot with $95 \%$ confidence intervals that shows that, for perceived distances between -4 and 0 (i.e perception of the government being to the left of the Sp), those who thought that the center-left coalition was the closest option for the Sp do not update their perceptions, while those who believed that a center-right coalition was closer do shift their beliefs about the position of 
the Sp toward the left (between -.5 and -2). Hence, even in a non-parametric setting our main hypothesis holds.

Figure B5: Local Polynomial Smooth Plot with 95\% Confidence Intervals (Distance RG-Sp on Update).

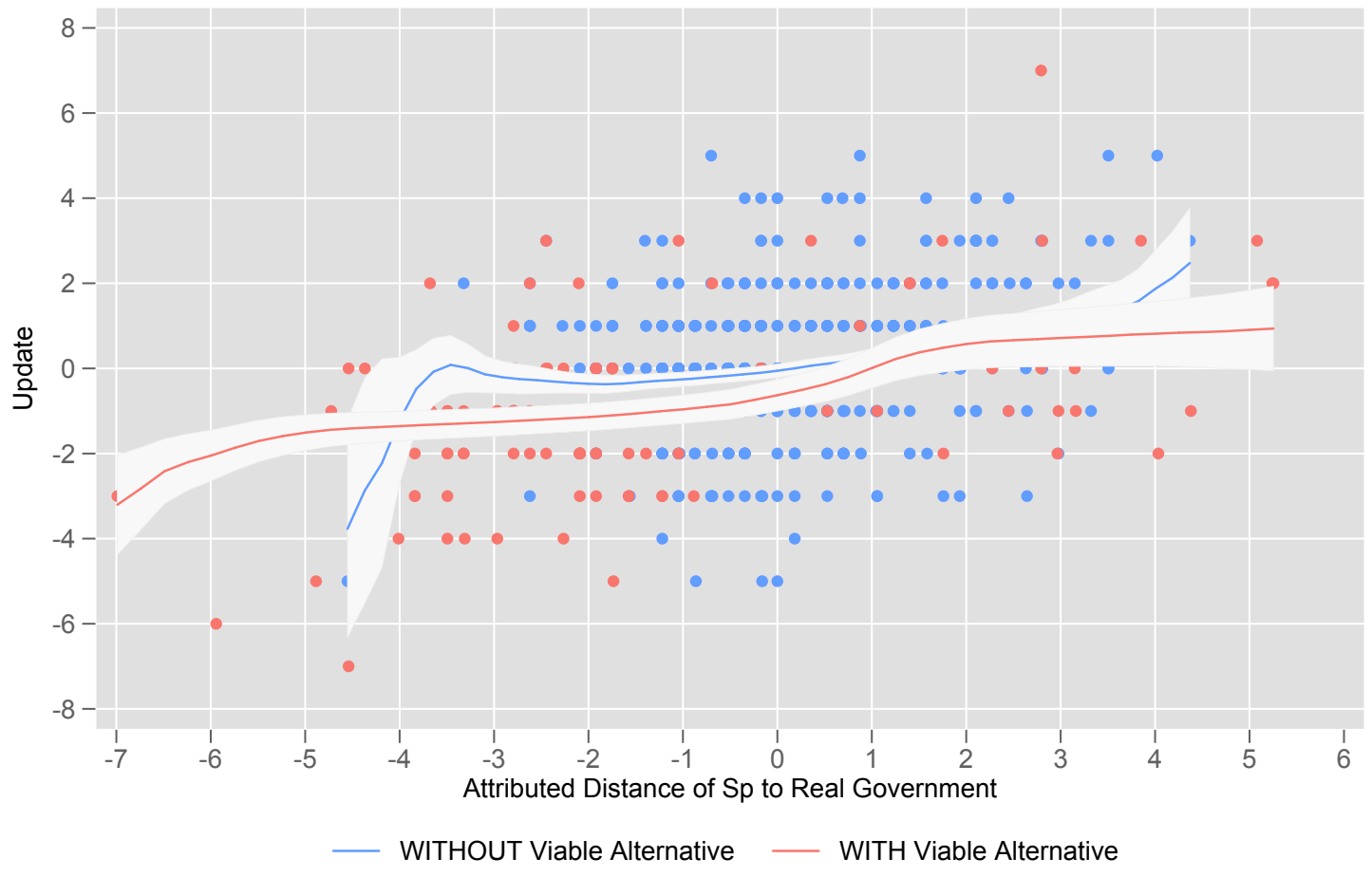

The final alternative explanation argues that the reason why some voters shifted their belief about the position of the Norwegian Center Party (Sp) toward the left had nothing to do with entry in a left-leaning coalition but with the fact that the Sp had made an explicit programmatic shift to the left between 2001 and 2005. Although that could not explain the difference between the two groups of respondents, we still address this possibility. Using data from the Manifesto Project (CMP) (Volkens et al., 2014) we can see that the Center Party did not move its program to the left in this time period. Indeed, while the 2001 manifesto scored -27.3 in the CMP left-right scale (with a potential range from -100 to +100 ), the 2005 one actually moved slightly to the right (-17.6). ${ }^{31}$ Hence, we can rule out that the change in voters' perceptions of the Sp position was driven by the party's manifesto.

${ }^{31}$ Source: https://visuals.manifesto-project.wzb.eu/mpdb-shiny/cmp_dashboard_dataset/ [Accessed February 15th, 2017]. 


\section{Supporting Information for Quasi-Experimental De- sign}

The following analysis assesses whether the timing in which survey respondents are contacted is orthogonal to their characteristics. For each case that we consider - the British Liberal Democrats in 2010 and the German FDP in 2009-, we present balance tests that compare respondents interviewed before and after the coalition is announced along several sociodemographic traits. ${ }^{32}$ If timing is indeed random, then both groups of respondents should not diverge with regard to these socio-demographic factors.

Table C1 presents such comparison for the case of Britain. The second column reports average demographic characteristics for the group of respondents who, in the post-election wave of the British Election Panel, were interviewed before the coalition formed, while the third column reports that of individuals interviewed afterwards. Results show that there are no systematic disparities in socio-demographic characteristics between both groups. Differences in average responses are small and in most cases these are not statistically distinguishable from zero. In the two instances were the difference is statistically significant — age and gender-, such divergence is substantively minimal and therefore we can attribute the statistical significance to the large sample size (over 13, 000 respondents).

Table C2 compares the pre and the post coalition groups within the post-election wave of the 2009 German Longitudinal Election Study. It also shows that there are no significant demographic differences across both groups. Hence, we can be more confident that the timing of participation in the survey is random and therefore it is uncorrelated with pre-existing views about the policy positions of political parties.

\footnotetext{
32 These traits are exogenous to short-term political events like the formation of a new cabinet. Therefore, if there were systematic differences across both groups then it would mean that the timing of survey participation is not random.
} 
Table C1: Balance tests. 2010 British Campaign Study.

\begin{tabular}{lccc}
\hline \hline & $\begin{array}{c}\text { before coalition } \\
\text { group }\end{array}$ & $\begin{array}{c}\text { after coalition } \\
\text { group }\end{array}$ & Difference \\
\hline marital status & 0.58 & 0.56 & -0.02 \\
gender & 0.49 & 0.54 & $0.05^{*}$ \\
education & 0.14 & 0.13 & 0.01 \\
income level & 7 & 7.1 & 0.1 \\
religious & 0.47 & 0.46 & 0.1 \\
housing & 0.78 & 0.77 & 0.01 \\
ethnicity & 0.04 & 0.04 & 0 \\
age & 51 & 49 & $2^{*}$ \\
trade union & 0.19 & 0.20 & 0.01 \\
Sample size $(\mathrm{N})$ & 11,231 & 2,125 & \\
\hline \hline
\end{tabular}

DATA SOURCE: 2010 pre-election wave British Election Study Internet Panel. Marital status indicates proportion of respondents that are currently married. Education reflects the proportion of participants that finished their full-time education at age 15 or earlier. Housing denotes the proportion that owns her current residence. Ethnicity is defined as the proportion of non-white respondents. Trade union indicates the proportion that declares to be a member of a trade union.

t-test: ${ }^{*} \mathrm{p}<.05$

Table C2: Balance tests. 2009 German Longitudinal Election Study.

\begin{tabular}{lccc}
\hline \hline & $\begin{array}{c}\text { before coalition } \\
\text { group }\end{array}$ & $\begin{array}{c}\text { after coalition } \\
\text { group }\end{array}$ & Difference \\
\hline age & 50 & 50 & 0 \\
gender & 0.50 & 0.55 & $0.05^{*}$ \\
marital status & 0.49 & 0.52 & 0.03 \\
household size & 2.1 & 2.1 & 0 \\
income level & 4.9 & 5.1 & 0.2 \\
education & 0.35 & 0.38 & 0.03 \\
employment & 0.36 & 0.33 & 0.03 \\
religious denomination & 0.27 & 0.24 & 0.03 \\
country of birth & 0.06 & 0.06 & 0 \\
from West Germany & $79 \%$ & $78 \%$ & $0.4 \%$ \\
Sample size $(\mathrm{N})$ & 894 & 1121 & \\
\hline \hline
\end{tabular}

DATA SOURCE: 2009 German Longitudinal Election Study (GLES), post-election wave. Education indicates the proportion of respondents with intermediary secondary education. Employment denotes the proportion of respondents with full-time jobs. Religious denomination defines respondents who belong to the German Protestant Church. Country of birth indicates the proportion of respondents born outside of Germany.

t-test: ${ }^{*} \mathrm{p}<.05$ 


\section{References in Supporting Information}

Benoit, Kenneth, Michael Laver and Slava Mikhaylov. 2009. "Treating Words as Data with Error: Uncertainty in Text Statements of Policy Positions." American Journal of Political Science 53(2):495-513.

Bowler, Shaun, Thomas Gschwend and Indridi H. Indridason. 2016. "Coalition Policy Perceptions." Manuscript.

Bräuninger, Thomas and Thomas König. 2005. "Indices of Power IOP 2.0." http://www. tbraeuninger.de/download/.

Carroll, Raymond J., David Ruppert and Leonard A. Stefanski. 1995. Measurement Error in Nonlinear Models. Chapman \& Hall.

Döring, Holger and Philip Manow. 2011. "Parliament and government composition database (ParlGov)." An infrastructure for empirical information on parties, elections and governments in modern democracies. Development Version. URL:http://dvn.eudo.eu/dvn/dv/parlgov [last accessed February 19, 2016].

Fortunato, David and James Adams. 2015. "How voters' perceptions of junior coalition partners depend on the prime minister's position." European Journal of Political Research 54(3):601-621.

Lederer, Wolfgang and Helmut Küchenhoff. 2006. "A Short Introduction to the SIMEX and MCSIMEX." The Newsletter of the $R$ Project 6(4):26.

Volkens, Andrea, Onawa Lacewell, Pola Lehmann, Sven Regel, Henrike Schultze and Annika Werner. 2014. The Manifesto Data Collection. Manifesto Project (MRG/CMP/MARPOR). Version 2014b. Berlin: Wissenschaftszentrum Berlin für Sozialforschung (WZB) https://manifestoproject.wzb.eu/ [accessed February 20, 2016]. 